\title{
Perfluorooctylbromide nanoparticles for ultrasound imaging and drug delivery
}

This article was published in the following Dove Press journal:

International Journal of Nanomedicine

Xiao Li

Zhongguo Sui

Xin Li

Wen Xu

Qie Guo

Jialin Sun

Fanbo Jing

Department of Clinical Pharmacy, The Affiliated Hospital of Qingdao University, Qingdao, Shandong,

People's Republic of China
Correspondence: Xiao Li; Fanbo Jing Department of Clinical Pharmacy, The Affiliated Hospital of Qingdao University, 16 jiangsu Road, Qingdao 266003 , Shandong, People's Republic of China Tel/fax +86538 29l 2263

Email lixiaoxiao0413@163.com; jingfanbol23@I63.com

\begin{abstract}
Perfluorooctylbromide nanoparticles (PFOB NPs) are a type of multifunctional nanotechnology that has been studied for various medical applications. Commercial ultrasound contrast agents (UCAs) suffer from the following limitations: short half-lives in vivo, high background signal and restricted distribution in the vascular circulation due to their micrometer dimensions. PFOB NPs are new potential UCAs that persist for long periods in the circulatory system, possess a relatively stable echogenic response without increasing the background signal and exhibit lower acoustic attenuation than commercial UCAs. Furthermore, PFOB NPs may also serve as drug delivery vehicles in which drugs are dissolved in the outer lipid or polymer layer for subsequent delivery to target sites in site-targeted therapy. The use of PFOB NPs as carriers has the potential advantage of selectively delivering payloads to the target site while improving visualization of the site using ultrasound (US) imaging. Unfortunately, the application of PFOB NPs to the field of ultrasonography has been limited because of the low intensity of US reflection. Numerous researchers have realized the potential use of PFOB NPs as UCAs and thus have developed alternative approaches to apply PFOB NPs in ultrasonography. In this article, we review the latest approaches for using PFOB NPs to enhance US imaging in vivo. In addition, this article emphasizes the application of PFOB NPs as promising drug delivery carriers for cancer and atherosclerosis treatments, as PFOB NPs can transport different drug payloads for various applications with good efficacy. We also note the challenges and future study directions for the application of PFOB NPs as both a delivery system for therapeutic agents and a diagnostic agent for ultrasonography.
\end{abstract}

Keywords: perfluorooctylbromide nanoparticles, ultrasound enhancement, drug delivery, therapy coupled with diagnosis

\section{Introduction}

Perfluorooctylbromide $\left(\mathrm{C}_{8} \mathrm{~F}_{17} \mathrm{Br}\right.$, PFOB; Figure 1), which is sometimes called as perflubron, is a linear perfluorocarbon (PFC) well known for its biocompatibility and good tolerance in human beings. ${ }^{1}$ PFOB is a dense, biochemically inert liquid with a high spreading coefficient. Unlike most PFCs, it is highly hydrophobic and shows small but finite lipophilicity due to the covalently bound bromine atom. ${ }^{2-5}$ Following in vivo administration, PFOB is not metabolized and instead is eliminated as a vapor from the body through exhalation via the lungs with a 3-day biological half-life. ${ }^{6}$

Nanoparticles (NPs), particularly polymer-based NPs, offer several advantages for anticancer drug/gene delivery. ${ }^{7,8}$ The small volume enables their progressive accumulation in the interstitial space of tumors through the enhanced permeation and retention (EPR) effect and endows them with a long circulation half-life. ${ }^{9}$ For in vivo ultrasound (US) imaging and drug delivery, PFOB is typically prepared as perfluorooctylbromide nanoparticles (PFOB NPs), which consist of a PFOB core encapsulated within a monolayer 


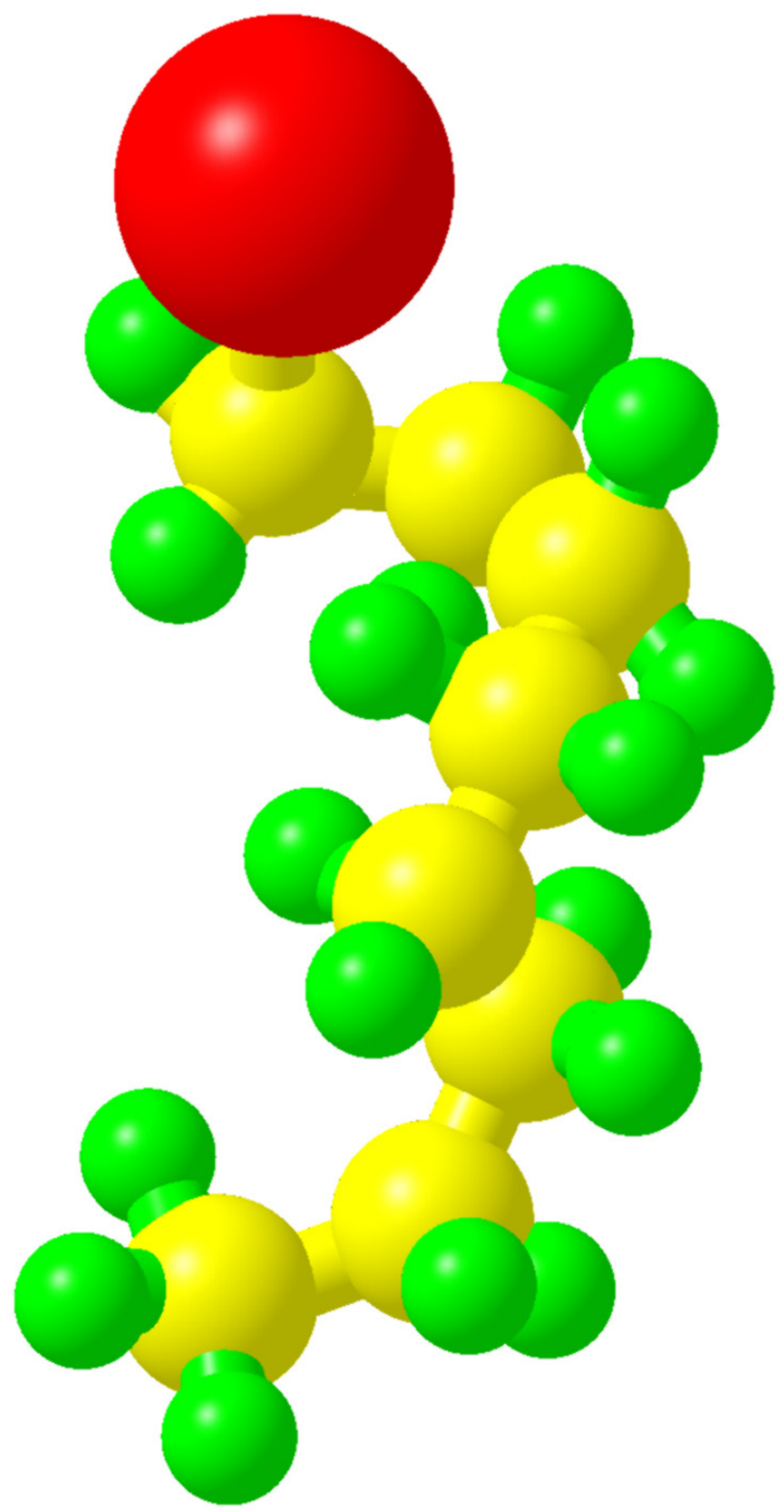

Figure I The structure of PFOB along with all atoms (red, bromine; yellow, carbon; green, fluorine).

Abbreviation: PFOB, perfluorooctylbromide.

of phospholipids or a polymeric shell. PFOB emulsions used in the clinic are marketed as LiquiVent (Alliance Pharmaceutical Corporation, San Diego, CA, USA), ${ }^{10}$ an oxygen-carrying liquid drug, and Oxygent ${ }^{\mathrm{TM}}$ (Alliance Pharmaceutical Corporation, San Diego, CA, USA), ${ }^{11}$ a blood substitution agent. In addition, the use of PFOB NPs in various medical applications, including ${ }^{19} \mathrm{~F}$ or ${ }^{1} \mathrm{H}$ magnetic resonance imaging (MRI) tracers, ${ }^{12-19}$ cell-tracking agents, ${ }^{20-22} \mathrm{X}$-ray contrast agents ${ }^{21,23}$ and computed tomography (CT) tracers, has been explored. ${ }^{24}$

US imaging is a clinical diagnostic technique that is frequently used because of its advantages, namely its real-time monitoring capability, low cost, high safety, convenience and portability. ${ }^{25}$ To improve the visualization in US imaging, US contrast agents (UCAs) have been developed. Mattrey et $\mathrm{al}^{26}$ reported that PFOB NPs considerably increased the echogenicity of the liver relative to that of the kidney 48 hours after intravenous infusion and produced an echogenic rim around VX2 carcinoma, thereby enhancing tumor detection. Therefore, the authors concluded that PFOB represented a promising US contrast material. Lanza et $\mathrm{al}^{27}$ reported that liquid PFC-filled NPs could potentially be used as new UCAs because of their long circulation half-life and acoustic stability. Since then, PFOB, one of the PFCs most frequently used as an NP core, ${ }^{28}$ has attracted the interest of researchers. PFOB NPs present a low intensity of US reflection and require higher concentrations or more binding events, which are the physical bases of the ability of PFOB NPs to serve as UCAs, to produce a relatively high backscatter signal. ${ }^{29,30}$ Because of its poor solubility in water and very low speed of sound(approximately $600 \mathrm{~m} / \mathrm{s}$ ), PFOB persists in the circulatory system for long periods and displays a relatively stable echogenic response. ${ }^{31}$ Consequently, PFOB NPs are designed for therapeutic applications, such as drug delivery or gene transfer, and for potential use as UCAs. The use of PFOB NPs as carriers has the potential advantage of selectively delivering payloads of therapeutic agents to the site of interest while improving the visualization of the site by US imaging. Nevertheless, an important question remains: Does this process really work? This review will focus on the use of PFOB NPs for US imaging and drug delivery in diagnosing and treating various diseases to determine the challenges in and provide future perspectives of the applications of PFOB NPs in targeted therapeutic delivery coupled with targeted US imaging.

\section{Structures of PFOB NPs}

For in vivo US imaging and drug delivery, PFOB is typically prepared as PFOB NPs with a surfactant coating for stabilization and functionalization (Figure 2). Typical PFOB NPs contain a lipid-surfactant mixture encapsulating a liquid core of PFOB using an oil-in-water emulsion solvent evaporation process. ${ }^{32-34}$ The surfactant mixture consists of phospholipids typically derived from either egg or soybean lecithin, which display good biocompatibility. These phospholipid preparations have been used for many applications such as cosmetic, food and drug applications owing to their safety. ${ }^{35}$ Thus, the final formulated PFOB NPs mainly comprise a PFOB core encapsulated within a lipid monolayer with a diameter $<1,000 \mathrm{~nm} .{ }^{36}$ Other typical PFOB NPs consist of poly(lactide-co-glycolide) acid (PLGA), ${ }^{37,38}$ poly(lactic 


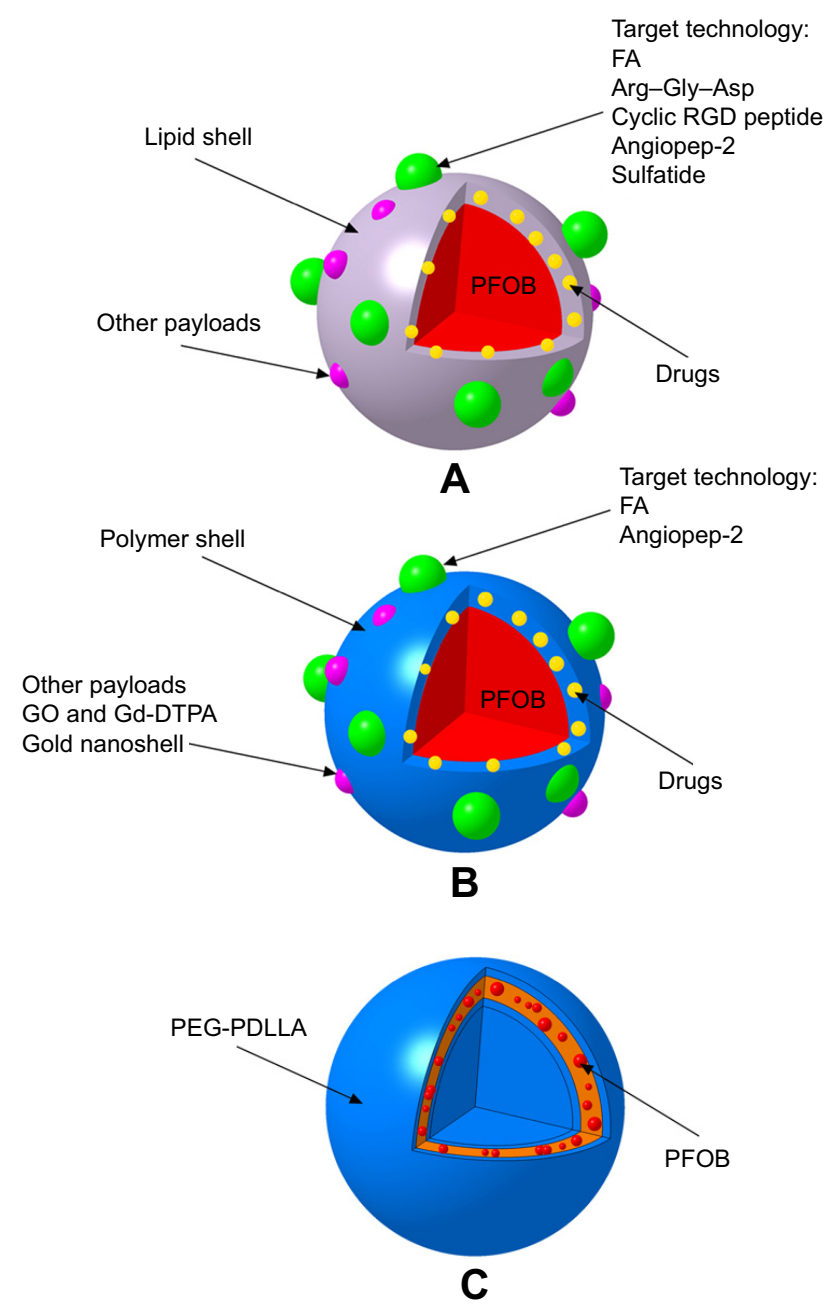

Figure 2 Schematic of the structures of PFOB NPs with different shells functionalized by different ligands.

Notes: (A) Representative images of typical PFOB NPs with a lipid shell for functionalization, representing an extremely versatile platform for targeted US/poo imaging and drug delivery applications. PFOB NPs carry drugs in the lipid layer of their shell. FA and Arg-Gly-Asp are used for ligand-directed, tissue-targeted US imaging. The targeting peptides Arg-Gly-Asp, a cyclic RGD peptide, angiopep-2 and sulfatide are used for ligand-directed tissue-targeted drug delivery. (B) Representative images of other typical PFOB NPs with a polymer shell for functionalization, representing an extremely versatile platform for US pool imaging and drug delivery applications. PFOB NPs carry drugs in the polymer layer of their shell or in the center of the PFOB NPs. FA and angiopep-2 are used for ligand-directed tissue-targeted drug delivery. (C) Representative images of novel self-assembled PFOB NPs with a low PFOB content in the outer lipophilic layer, representing a platform for US pool imaging.

Abbreviations: FA, folic acid; Gd-DTPA, gadolinium diethylene triamine pentacetate acid; GO, graphene oxide; PEG-PDLLA, poly(ethylene glycol)-b-poly(D,L-lactic acid); PFOB, perfluorooctylbromide; PFOB NPs, perfluorooctylbromide nanoparticles; US, ultrasound.

acid) (PLA) $)^{39}$ or another polymer ${ }^{26,40}$ encapsulating a liquid PFOB core prepared using an oil-in-water emulsion solvent evaporation process. ${ }^{41}$ These polymers are biodegradable, are widely used in drug products and possess good general biocompatibility. ${ }^{42,43}$ An amphiphilic block copolymer, poly(ethylene glycol)- $b$-poly(D,L-lactic acid) (PEG-PDLLA), was developed to construct novel self-assembled PFOB NPs with a low content of PFOB in the outer lipophilic layer. ${ }^{44}$
This self-assembled structure has mainly been studied as a UCA and has been established as a type of PFOB NP. The particle shell formulations and main applications, which are described in the text, are summarized in Table 1. Schematics showing the structures of PFOB NPs with different shells functionalized by different ligands are shown in Figure 2.

\section{PFOB NPs for US imaging}

Commercial UCAs (eg, Optison ${ }^{\mathrm{TM}}$ (Mallinckrodt Inc., St. Louis, MO, USA) and Definity ${ }^{\circledR}$ (Lantheus Medical Imaging, N. Billerica, MA, USA) ${ }^{46}$ comprise encapsulated gas microbubbles with a diameter between approximately 2 and $10 \mu \mathrm{m}$. Upon intravenous injection, these UCAs are restricted to the vascular system of perfused organs or tissues. Despite the very sensitive detection offered by the strong nonlinear response of microbubbles, these agents present several limitations due to their short half-lives in vivo and high background signal. Because of their micrometer dimensions, their transportation in the vascular circulation is restricted to only a few minutes, and they cannot traverse outside highly permeable tumor vessels with pores ranging from 400 to $600 \mathrm{~nm}$ in diameter to achieve tumor imaging. ${ }^{47}$ Compared with microbubbles, NPs offer several advantages in targeted US imaging. Their small volume contributes to a long circulation half-life and enables their progressive accumulation in the interstitial space of tumors through the enhanced EPR. ${ }^{9}$ These NPs have primarily been designed to address key issues, such as longevity and stability in the body.

PFOB was encapsulated within a Pluronic F-68 shell with a diameter of approximately $500 \mathrm{~nm}$ by Mattrey et al. ${ }^{26}$ The resulting PFOB NPs considerably increased the echogenicity of the liver relative to that of the kidney 48 hours after intravenous infusion and produced an echogenic rim around VX2 carcinoma in New Zealand white rabbits, thereby enhancing tumor detection. Therefore, the authors concluded that PFOB NPs represent a promising UCA for selectively increasing detection in the liver and in tumors. ${ }^{26}$ According to Lanza et $\mathrm{al}^{27}$ targeted perfluorodichlorooctane (PFDCO)-filled NPs (PFDCO NPs) markedly enhance the acoustic reflectivity of thrombi in vivo in a canine model. Targeted PFDCO NPs persist in the blood for a long period, specifically bind to pretargeted fibrin and generate a marked acoustical enhancement of acute vascular thrombi without increasing the background signal. In their follow-up study, the authors reported that both targeted PFOB NPs and targeted PFDCO NPs significantly increased the acoustic reflectivity of the nitrocellulose membrane samples and plasma thrombus substrate samples compared with their individual baseline values. Targeted 
Table I Broad applications of PFOB NPs

\begin{tabular}{|c|c|c|c|c|}
\hline No. & Main component of the shell & Application & Target epitope & References \\
\hline \multirow[t]{2}{*}{ I } & Polymer (PLGA, PCL, PLA, PEG- & US pool imaging & & $9,28,39,44,52,58$ \\
\hline & PDLLA or PLGA-PEG and ingredients) & & & \\
\hline \multirow[t]{2}{*}{2} & Lipids (lecithin, cholesterol and & US pool imaging & - & 30 \\
\hline & ingredients) & Tumor-targeted US imaging & FR or $\alpha_{v} \beta_{3}$ integrin & $63,71,72$ \\
\hline 3 & $\begin{array}{l}\text { Lipids (lecithin, cholesterol and } \\
\text { ingredients) }\end{array}$ & $\begin{array}{l}\text { Loading different drugs for } \\
\text { several therapies }\end{array}$ & $\begin{array}{l}\text { VCAM-I, } \alpha_{\mathrm{v}} \beta_{3} \text { integrin, } \alpha_{5} \beta_{1} \\
\text { integrin, TN-C or LRP-I }\end{array}$ & $\begin{array}{l}33,96,99,104,105 \\
119-122,127-129\end{array}$ \\
\hline 4 & $\begin{array}{l}\text { Polymer (PLGA-PEG, } \mathrm{Bi}_{2} \mathrm{Se}_{3} \text { or PLGA } \\
\text { and ingredients) }\end{array}$ & Cancer therapy & LRP-I or none & $17,106,107,112$ \\
\hline
\end{tabular}

Abbreviations: FR, folate receptor; LRP-I, low-density lipoprotein receptor-related protein-I; PCL, polycaprolactone; PEG-PDLLA, poly(ethylene glycol)-b-poly(D,L-lactic acid); PFOB NPs, perfluorooctylbromide nanoparticles; PLA, poly(lactic acid); PLGA, poly(lactide-co-glycolide) acid; PLGA-PEG, poly(lactide-co-glycolide) acid-polyethylene glycol; TN-C, tenascin-C; US, ultrasound; VCAM-I, vascular cell adhesion molecule I.

PFOB NPs and targeted PFDCO NPs enhanced reflectivity on both nitrocellulose membrane and plasma thrombus substrates to nearly identical levels. ${ }^{29}$ Thus, US imaging with site-targeted PFOB NPs is expected to improve the diagnosis and detection of specific pathologies and tissue types, such as fibrin, as described earlier. PFOB NPs, which are resistant to pressure changes and mechanical stress, possess a relatively stable echogenic response without increasing the background signal, exhibit low acoustic attenuation and have received substantial attention with regard to fabricating a new UCA that can overcome the limitations of microbubble UCAs. Unfortunately, PFOB NPs are relatively incompressible and thus generally produce relatively poor echogenicity $27,30,48$ in circulation. Thus, the low intensity of US reflection has limited the application of PFOB NPs in the field of ultrasonography. Therefore, how to overcome the limitations of PFOB NPs in ultrasonography remains an open question. Accordingly, different researchers have developed alternative approaches to apply PFOB NPs in ultrasonography.

\section{Adaptation of ultrasonography parameters for blood pool imaging}

Some researchers have adapted ultrasonography parameters for blood pool imaging. High-frequency US (HFU), also known as US biomicroscopy, ${ }^{49}$ is an established tool for imaging human beings and small animals in vivo. ${ }^{50}$ Some researchers have reported the feasibility of detecting thick PLGA-shelled PFOB NPs at a high frequency and explored the ranges of concentrations, acoustic pressures and pulse durations capable of detecting the PLGA-shelled PFOB NPs in the 20-40 MHz frequency range. ${ }^{28}$ Although the detectability of PFOB NPs would potentially be improved by HFU $(>15 \mathrm{MHz})$, the acoustic responses remain relatively weak. ${ }^{28}$ PFOB NPs exhibit a low inherent echogenicity and are poor blood pool contrast agents when employed under the conditions used for conventional two-dimensional (2D) echocardiography or harmonic imaging or when imaged with color flow or spectral Doppler. ${ }^{30}$ Thus, a new ultrasonic imaging modality, power Doppler harmonic imaging (PDHI), has been introduced. ${ }^{51}$ Wickline et $\mathrm{l}^{30}$ have shown that PFOB NPs coated with a lipid shell with a mean diameter of approximately $400 \mathrm{~nm}$ provide excellent blood pool contrast when using PDHI at PFOB NP doses of $0.5 \mathrm{~mL} / \mathrm{kg}$. The contrast effect was unaffected by continuous US imaging at high transducer power outputs and persisted for more than 1 hour. ${ }^{30} \mathrm{Li}$ et al ${ }^{52}$ intravenously injected New Zealand white rabbits with PFOB NPs with a PLA shell for US imaging of their kidneys using both pulse inversion harmonic imaging (PIHI) mode and conventional B-mode. The rabbit kidney was more clearly observed using PIHI mode than using B-mode US imaging. These results were consistent with the abovementioned observations.

\section{Adaptation of the formulations designed for blood pool imaging}

The mechanical properties of PFOB NPs are very important for their use as UCAs because USs are mechanical waves. ${ }^{53}$ In the classical mechanics of shells, the mechanical properties usually depend on the shell thickness-to-radius ratio. Pisani et a $l^{53}$ concluded that the shell thickness-to-radius ratio depends only on the PFOB/PLGA ratio and that this versatile process could be adapted to other biodegradable polymers. In their follow-up study, ${ }^{41}$ the authors designed a process to obtain PFOB NPs within a PLGA shell of homogeneous thickness to develop more stable UCAs. Flegg et $\mathrm{al}^{40}$ applied a novel modified theory based on Rayleigh scattering of US to a UCA consisting of PFOB encapsulated in polycaprolactone (PCL) and concluded that the shell of the PFOB NPs may play important roles in the scattering from each PFOB NP and the echogenicity of an agglomeration of PFOB NPs. Because the modulation of the thickness-to-radius ratio of PLGA and PFOB allows researchers to tune the compressibility and echogenicity of PFOB NPs in vitro, Jafari et $\mathrm{al}^{28}$ compared the 
US responses of PFOB NPs with a PLGA shell of different thicknesses. Diou et $\mathrm{al}^{54}$ also utilized the very same strategy with PEGylated PFOB NPs with a PLGA shell to optimize their echogenicity. The results are consistent with a previous report by Pisani et $\mathrm{al}^{53}$ showing that the thickness of the PFOB NP shell is an important parameter for US contrast enhancement. However, the acoustic responses remain relatively weak, and additional experiments are necessary to further modify PFOB NPs and obtain a better acoustic response. ${ }^{28}$

Consequently, subsequent studies have adapted formulations designed for blood pool imaging but have met with limited success in vivo. ${ }^{55-57}$ Meanwhile, several researchers have successfully designed PFOB NPs for use in blood pool imaging.

According to Pisani et al, ${ }^{9}$ the thickness of the PFOB NP shell is an important parameter for US contrast enhancement: thinner shells produce a larger signal-to-noise ratio (SNR) and more compressible PFOB NPs. These authors have designed PFOB NPs with a thick PLGA shell as a blood pool contrast agent. The initial bolus passage enables significant US enhancement of the blood pool in mice during hepatic imaging (14 MHz, tissue harmonic imaging [THI] mode) after intravenous injection. ${ }^{9}$ Similar multifunctional UCAs featuring gold nanoshells coating the outside of PFOB NPs with a PLA shell have been designed by Ke et $\mathrm{al}^{58}$ and integrated with superparamagnetic iron oxide (SPIO) dissolved in PFOB for combined dual-mode US/CT imaging-guided photothermal tumor ablation. Their platform is different from the PFOB NPs developed by our laboratory or by other researchers, which presented a spherical shape with a smooth surface (Figure 3A), while their PFOB NPs with the gold nanoshell coating presented a rather rough surface morphology (Figure 3B). Several seconds after intravenous injection of their PFOB NPs, the rabbit kidneys showed clear enhancement under the PIHI contrast mode (mechanical index [MI] of 0.70). However, the authors believed that the US contrast enhancement was provided by the PFOB inside and that SPIO was used to obtain more accurate diagnostic information from contrast-enhanced MRI images. We are skeptical about this hypothesis. SPIO has also been utilized as a US imaging material in many studies. ${ }^{25,59,60}$ Therefore, the US enhancement may be caused by the SPIO, not the PFOB, in their formulation. In the same year, Ke et $\mathrm{al}^{39}$ also designed another multifunctional UCA using a gold nanoshell coating the outside of PFOB NPs with a PLA shell for combined dual-mode US/CT imaging and photothermal cancer therapy. The rabbit kidney showed clear enhancement in PIHI contrast mode (at an MI of 0.59) after intravenous injection of their PFOB NPs. ${ }^{39}$ A novel multifunctional theranostic UCA using PFOB NPs with a PLA shell surface functionalized with graphene oxide (GO) and a gadolinium diethylene triamine pentacetate acid (Gd-DTPA) was successfully fabricated by Li et al. ${ }^{52}$ Again, the rabbit kidney showed clear enhancement in PIHI contrast mode (at an MI of 0.42) after intravenous injection of their PFOB NPs. ${ }^{52}$ Other novel PFOB NPs with an extremely low PFOB content were prepared through the selfassembly of an amphiphilic block copolymer, PEG-PDLLA (Figure 2C). After intravenous injection of these PFOB NPs, all cavities of the heart, liver and kidney, particularly the
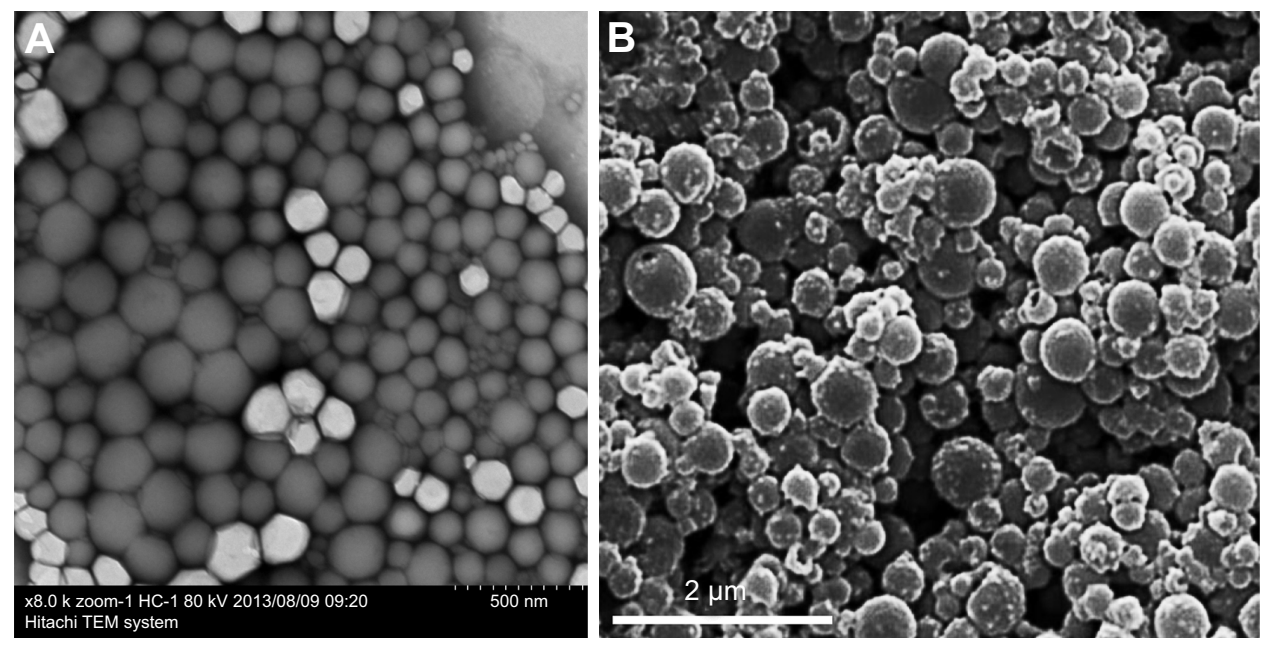

Figure 3 TEM images of normal PFOB NPs (A). TEM images of PFOB NPs coated with a gold nanoshell (B).

Notes: (A) Reprinted from Li X, Qin F, Yang L, Mo L, Li L, Hou L. Sulfatide-containing lipid perfluorooctylbromide nanoparticles as paclitaxel vehicles targeting breast carcinoma. Int J Nanomedicine. 20I4;9:397I-3985. ${ }^{33}$ (B) Reprinted from the study by Ke H, Wang J, Tong S, Jin Y, Wang S, Qu E, Bao G, Dai Z. Gold Nanoshelled Liquid Perfluorocarbon Magnetic Nanocapsules: a Nanotheranostic Platform for Bimodal Ultrasound/Magnetic Resonance Imaging Guided Photothermal Tumor Ablation. Theranostics 2014;4(I):I2-23. doi:I0.7I50/thno.7275. Available from http://www.thno.org/v04p0012.htm..$^{58}$

Abbreviations: PFOB NPs, perfluorooctylbromide nanoparticles; TEM, transmission electron microscope. 
horizontal axis of the right kidney, displayed a slight and homogeneous enhancement without any highlighted spots, which indicated a good contrast enhancement effect for blood pool imaging. The authors believed that both the compressibility and shell density of their PFOB NPs serving as US scatterers were enhanced, resulting in a much higher echo intensity than that of other PFOB formulations. ${ }^{44}$

\section{Fabrication of targeted PFOB NPs for tissue-targeted imaging}

PFOB NPs may be less liable to nonspecific signal enhancement events since larger concentrations (more binding events) are required to produce a relatively high echogenicity. ${ }^{29,61}$ Thus, a high contrast between specific and nonspecific agents may be obtained by adding a targeted ligand to PFOB NPs. Although nanosized UCAs achieve passive imaging of tumors via the EPR effect, the specific capability of nanosized UCAs to bind to tumor tissues to achieve US enhancement is still limited. ${ }^{62}$ Some investigators have recognized the future clinical importance of PFOB NPs in tumor-targeted US imaging and developed targeted PFOB NPs to enhance US imaging; however, this objective was realized only in vitro. ${ }^{61}$ Subsequently, PFOB NPs targeted to $\alpha_{\mathrm{v}} \beta_{3}$ integrins expressed on new vessels in tumors were formulated by adding an "Arg-Gly-Asp" mimetic binding ligand to the lipid layer. ${ }^{63}$ Tumor-specific enhanced imaging was accomplished by either $\mathrm{I}_{f}(1.99)$ or $\mathrm{H}_{f}$ receivers (different receivers of ultrasonography) in transgenic K14-HPV16 mice whose ears typically carried squamous metaplasia after intravenous injection of these targeted PFOB NPs. ${ }^{63}$ Another laboratory modified the surface of PFOB NPs with PEGylated phospholipids to allow them to escape recognition and clearance from the mononuclear phagocyte system and achieve passive tumor targeting. In this study, tumors were observed by ultrasonography only after intratumoral injection. To explain the absence of an echogenic signal in the tumor after intravenous injection of these PEGylated PFOB NPs, a histological analysis was conducted, revealing their limited accumulation within the tumor tissue at a level that was not sufficient to achieve US imaging enhancement. ${ }^{64}$ The folate receptor (FR) binds to folic acid (FA) with high affinity and mediates its intracellular transport via receptor-mediated endocytosis. ${ }^{65}$ The FR is overexpressed on the surface of various types of tumors, including pancreatic, prostate, lung, head and neck, breast, ovarian and mesothelioma tumors, whereas it shows limited expression and restricted distribution in normal tissue ${ }^{66-70} \mathrm{Hu}$ et al ${ }^{71}$ bound an FA-polyethylene glycol (PEG)chitosan (CS) conjugate to PFOB NPs through electrostatic interactions, promoting the formation of new FR-mediated PFOB NPs using a layer-by-layer assembly technique. The US signals of the NPs in vitro increased as the concentration of the FR-mediated PFOB NPs increased. Based on the experimental results, the authors predicted that the FR-mediated PFOB NPs are more promising agents for tumor-targeted US imaging. ${ }^{71}$ In a subsequent study, ${ }^{72}$ the researchers injected their FR-mediated PFOB NPs along with an immobilized probe into mice via the tail vein and set the ultrasonography parameters to an MI of 0.7 and a gain of $80 \%$. Between 20 and 160 minutes after injection, the images from FR-overexpressing tumors displayed a higher intensity value than those from tumors expressing low levels of FR. Thus, the FR-mediated PFOB NPs achieved specific enhanced imaging of FR-overexpressing tumors and a longer duration of effective enhanced US imaging. ${ }^{72}$ The abovementioned alternative approaches to applying PFOB NPs in ultrasonography are summarized in Table 2.

\section{PFOB NPs for drug delivery}

PFOB NPs have been formulated to adhere to the surface of a target and produce highly concentrated zones. ${ }^{61}$ These targeted imaging effects may persist in the body from several minutes to possibly several days. ${ }^{73}$ Therefore, a new generation of PFOB NPs as stable UCAs designed for therapeutic applications such as drug delivery or gene transfer has become available. ${ }^{53}$ With the attachment of targeting ligands to the PFOB NP surface, PFOB NPs have been specifically directed to bind biomarkers of cancer, angiogenesis, thrombosis and other diseases. ${ }^{74}$ Furthermore, targeting PFOB NPs to the tissue of interest also localizes drug release to the target site, resulting in a much higher effective drug concentration at that site. In addition, PFOB NPs may function as an efficacious drug delivery vehicle because their safety has been approved by the Food and Drug Administration (FDA) ${ }^{75}$ PFOB NPs may serve as drug delivery vehicles in which drugs are dissolved in the outer lipid or polymer layer for subsequent delivery to target cells for site-targeted therapy. Therefore, many researchers have designed PFOB NPs with a drug or gene ${ }^{76}$ payload as effective systems for delivery to a targeted site. In contrast to liposomal drug delivery, which generally requires endocytosis, the mechanism by which targeted PFOB NPs with a lipid-coating transport drugs involves lipid exchange or lipid mixing between the lipid monolayer of the delivery system and the targeted cell membrane, termed "contactfacilitated drug delivery." $77-80$ PFOB NPs have been loaded with different drugs for various applications, such as antiinflammatory arthritis therapy, ${ }^{32,81,82}$ bone fracture healing, ${ }^{83,84}$ dust mite-triggered asthma therapy, ${ }^{85}$ cytotoxicity reduction in the loaded drug, ${ }^{86}$ analyses of complement activation, ${ }^{87}$ thrombolytic therapy, ${ }^{88,89}$ prevention of restenosis, ${ }^{77,90}$ atherosclerosis therapy and cancer therapy. The capacity 
Table 2 Alternative approaches for applying PFOB NPs to ultrasonography in vivo

\begin{tabular}{|c|c|c|c|c|}
\hline $\begin{array}{l}\text { Methods to achieve } \\
\text { US imaging }\end{array}$ & $\begin{array}{l}\text { Component } \\
\text { of the shell }\end{array}$ & $\begin{array}{l}\text { Target } \\
\text { epitope }\end{array}$ & Main points & References \\
\hline $\begin{array}{l}\text { Adaptation of } \\
\text { ultrasonography }\end{array}$ & PLGA & - & $\begin{array}{l}\text { The detectability of PFOB NPs may potentially be } \\
\text { improved using HFU }\end{array}$ & 28 \\
\hline \multirow[t]{2}{*}{ parameters } & $\begin{array}{l}\text { Lecithin and } \\
\text { cholesterol }\end{array}$ & - & $\begin{array}{l}\text { PFOB NPs provided excellent blood pool contrast images } \\
\text { with PDHI for }>\text { I hour }\end{array}$ & 30 \\
\hline & PLA & - & $\begin{array}{l}\text { Novel multifunctional PFOB NPs were fabricated by } \\
\text { loading PFOB into a PLA shell followed by surface } \\
\text { functionalization with GO and Gd-DTPA } \\
\text { The rabbit kidney was more clearly observed in PIHI } \\
\text { mode than in B-mode US imaging }\end{array}$ & 52 \\
\hline \multirow[t]{5}{*}{$\begin{array}{l}\text { Adaptation of } \\
\text { formulations }\end{array}$} & PLGA & - & $\begin{array}{l}\text { A thinner shell produces a larger SNR and more } \\
\text { compressible PFOB NPs } \\
\text { PFOB NPs with a thick PLGA shell present a significant } \\
\text { US enhancement of the blood pool during hepatic imaging }\end{array}$ & 9 \\
\hline & PLA & - & $\begin{array}{l}\text { Novel multifunctional PFOB NPs were fabricated by } \\
\text { loading PFOB and SPIO into a PLA shell followed by } \\
\text { surface functionalization with a PEGylated gold nanoshell } \\
\text { The kidney of the rabbit showed obvious enhancement in } \\
\text { PIHI contrast mode }\end{array}$ & 58 \\
\hline & PLA & - & $\begin{array}{l}\text { Multifunctional PFOB NPs underwent surface } \\
\text { functionalization with a PEGylated gold nanoshell } \\
\text { The kidney of the rabbit showed obvious enhancement in } \\
\text { PIHI contrast mode }\end{array}$ & 39 \\
\hline & PLA & - & $\begin{array}{l}\text { Novel multifunctional PFOB NPs were fabricated by } \\
\text { loading PFOB intoa PLA shell followed by surface } \\
\text { functionalization with GO and Gd-DTPA } \\
\text { The rabbit kidney showed obvious enhancement in PIHI } \\
\text { contrast mode }\end{array}$ & 52 \\
\hline & PEG-PDLLA & - & $\begin{array}{l}\text { All cavities of the heart, liver and kidney, particularly the } \\
\text { horizontal axis of the right kidney, showed slight and } \\
\text { homogeneous enhancement without any highlighted spots }\end{array}$ & 44 \\
\hline \multirow[t]{2}{*}{$\begin{array}{l}\text { Fabrication of } \\
\text { targeted UCAs }\end{array}$} & $\begin{array}{l}\text { Lecithin and } \\
\text { cholesterol }\end{array}$ & $\begin{array}{l}\alpha_{v} \beta_{3} \\
\text { integrin }\end{array}$ & $\begin{array}{l}\text { Specific enhanced US imaging was achieved in transgenic } \\
\text { mice whose ears exhibited squamous metaplasia }\end{array}$ & 63 \\
\hline & $\begin{array}{l}\text { Lecithin and } \\
\text { cholesterol }\end{array}$ & $\mathrm{FR}$ & $\begin{array}{l}\text { Images from the FR-overexpressing tumors displayed } \\
\text { a higher intensity value than images from tumors } \\
\text { expressing low levels of FR }\end{array}$ & 72 \\
\hline
\end{tabular}

Abbreviations: FR, folate receptor; Gd-DTPA, gadolinium chelate; GO, graphene oxide; HFU, high-frequency US; PDHI, power Doppler harmonic imaging; PEG-PDLLA, poly(ethylene glycol)-b-poly(D,L-lactic acid); PFOB, perfluorooctylbromide; PFOB NPs, perfluorooctylbromide nanoparticles; PIHI, pulse inversion harmonic imaging; PLA, poly(lactic acid); PLGA, poly(lactide-co-glycolide) acid; SNR, signal-to-noise ratio; SPIO, superparamagnetic iron oxide; UCAs, US contrast agents; US, ultrasound.

to deliver a payload to the targeted site could be of great benefit, leading to the development of targeted anticancer and anti-atherosclerosis therapeutics based on this platform.

\section{Drug delivery for cancer therapy}

Although a number of anticancer drugs have been tested clinically, either their low uptake efficacy at the target or systemic toxicity has limited their therapeutic value. ${ }^{91-93}$ A satisfactory delivery vehicle can facilitate improved pharmacokinetics and biodistribution, decreased toxicities, improved solubility and stability and controlled release. ${ }^{94,95}$ PFOB NPs represent a potential suitable delivery vehicle, and surface functionalization of these NPs may improve the tolerability, site-specific delivery and controlled release of therapeutic agents. ${ }^{33}$
Soman et $\mathrm{al}^{96}$ incorporated melittin into the outer lipid monolayer of PFOB NPs. The favorable pharmacokinetics of PFOB NPs allow melittin to accumulate in murine tumors in vivo and produce an obvious reduction in tumor growth without any apparent toxicity compared with melittin alone. ${ }^{96}$ Vascular cell adhesion molecule 1 (VCAM-1), which is expressed in tumor and atherosclerotic vessels, plays a pivotal role in the course of many inflammatory diseases. ${ }^{97-101}$ VCAM-1-targeted PFOB NPs were generated by Pan et al ${ }^{99}$ for in vivo targeting in breast cancer (STAT-1-deficient) models. The authors observed a 4.9-fold increase in the number of targeted PFOB NPs in the tumor vasculature compared with nontargeted PFOB NPs, indicating that VCAM-1-targeted PFOB NPs may function as an ideal breast cancer-targeted delivery system for certain anticancer drugs.${ }^{99}$ Sulfatide is a 
ligand of several extracellular matrix (ECM) glycoproteins, particularly tenascin-C (TN-C), which is highly upregulated in many different cancers, including breast, ovarian and prostate cancer. ${ }^{102,103}$ Sulfatide, a type of lipid, actively incorporates with other lipids in PFOB NPs and functions as part of the outer lipid monolayer component of the targeted ligand. ${ }^{33} \mathrm{We}$ added sulfatide to PFOB NPs as a targeted delivery system for loading paclitaxel (PTX) to treat breast carcinoma. These sulfatide-targeted PFOB NPs were observed in breast cancer tissues, facilitated the delivery of the drug to the targeted breast cancer tumor (Figure 4) and improved the therapeutic outcomes of PTX in a mouse model (Figure 5). ${ }^{33}$ Pan et al ${ }^{104}$ incorporated a c-Myc inhibitor prodrug into $\alpha_{\mathrm{v}} \beta_{3}$-targeted PFOB NPs and reported that the formulation displayed good
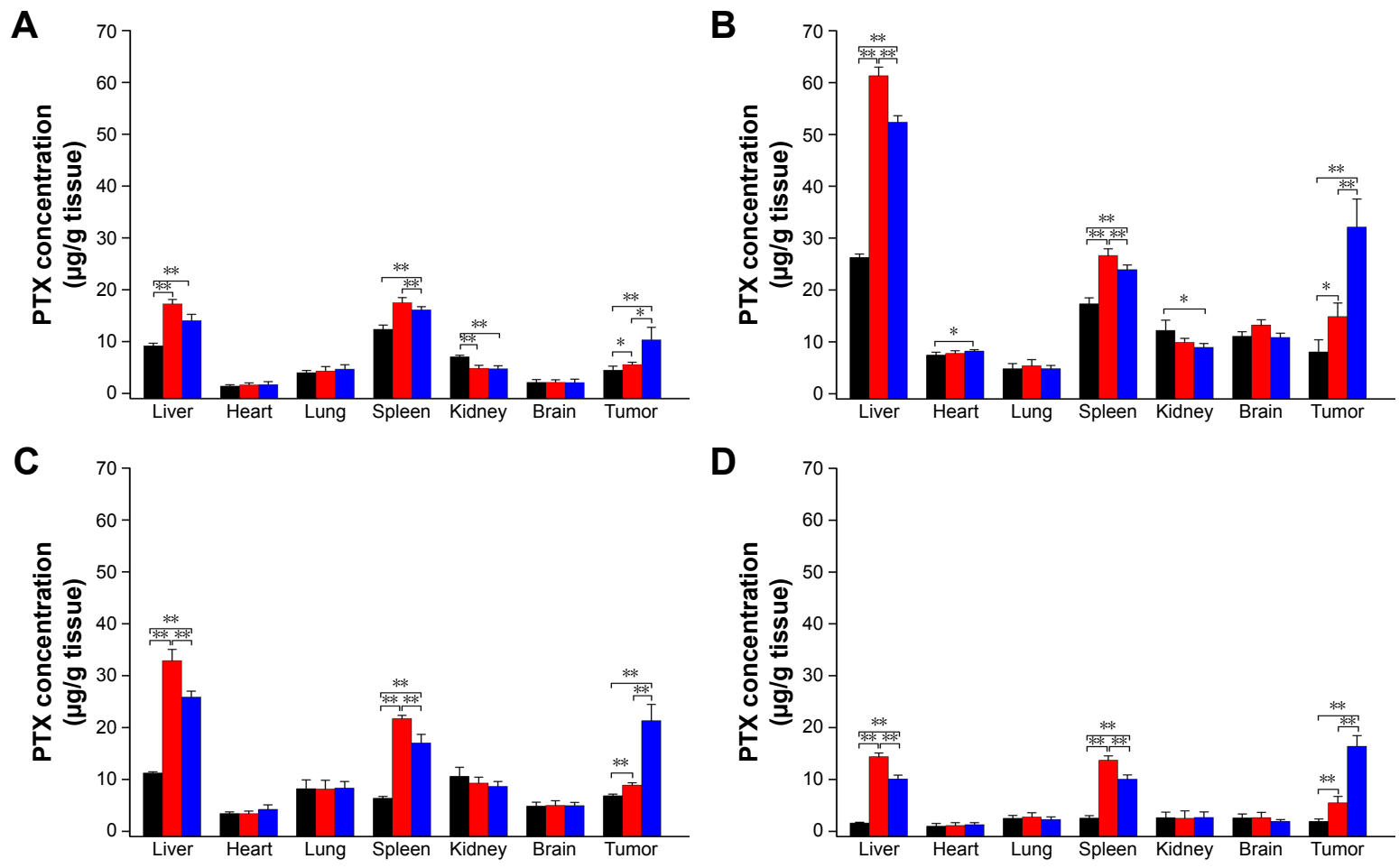

\begin{tabular}{|l|l|}
\hline Taxol PTX-NPs & PTX-SNPs \\
\hline
\end{tabular}
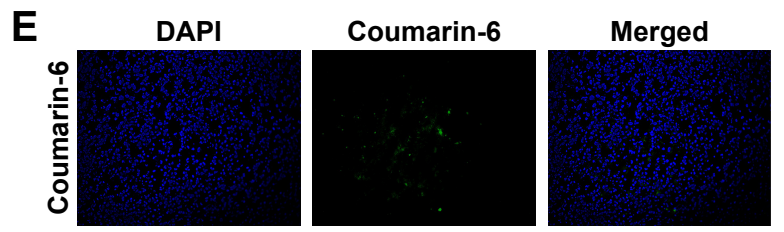

$\mathbf{F}$
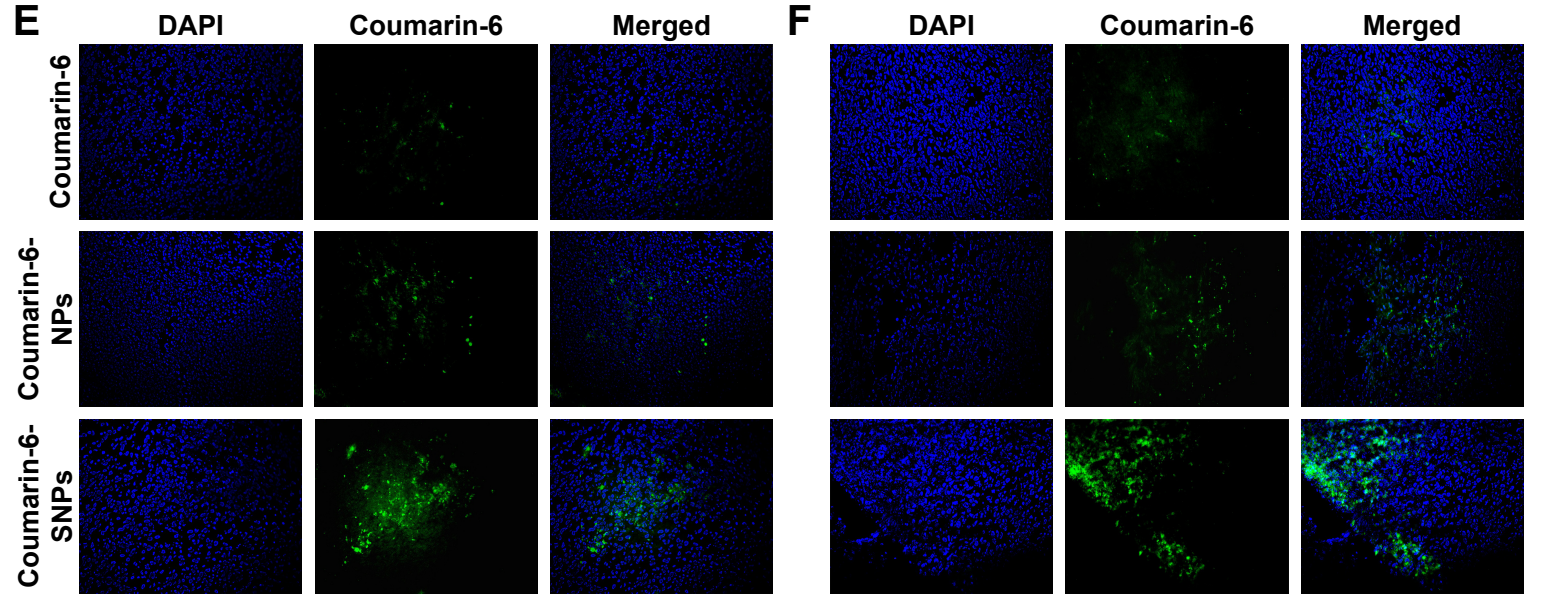

Figure 4 Images of the tissue distribution of PTX in EMT6 tumor-bearing mice obtained at I hour (A), 8 hours (B), 12 hours (C) and 24 hours (D) after intravenous administration of different PTX formulations. Values are presented as mean $\pm S D(n=3)$. $* P<0.05$, $* * P<0.0$ I. (E) Representative images of the fluorescence of different coumarin-6 formulations in frozen slices of breast tumor tissues I hour after administration. (F) Representative images of the fluorescence of different coumarin-6 formulations in frozen slices of breast tumor tissue 8 hours after administration. Representative images of tumor sections were obtained at 200× magnification. PTX-NPs, PFOB NPs loaded with PTX; PTX-SNPs, sulfatide-targeted PFOB NPs loaded with PTX; coumarin-6-NPs, PFOB NPs loaded with coumarin-6; coumarin-6-SNPs, sulfatidetargeted PFOB NPs loaded with coumarin-6.

Note: Reprinted from Li X, Qin F, Yang L, Mo L, Li L, Hou L. Sulfatide-containing lipid perfluorooctylbromide nanoparticles as paclitaxel vehicles targeting breast carcinoma. Int J Nanomedicine. 2014;9:397I-3985. ${ }^{33}$

Abbreviations: PFOB NPs, perfluorooctylbromide nanoparticles; PTX, paclitaxel; SNPs, sulfatide-targeted perfluorooctylbromide nanoparticles. 


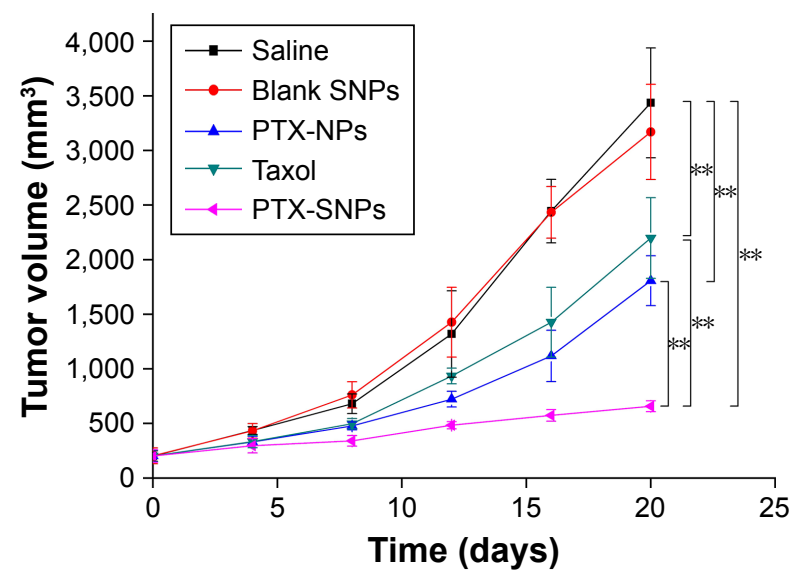

Figure 5 Tumor growth curves of EMT6 tumor-bearing mice after the administration of different PTX formulations.

Notes: Values are presented as mean \pm SD $(n=6)$. PTX-NPs, PFOB NPs loaded with PTX; PTX-SNPs, sulfatide-targeted PFOB NPs loaded with PTX; blank SNPs, sulfatidetargeted PFOB NPs. ${ }^{*} p<<0.01$. Reprinted from Li X, Qin F, Yang L, Mo L, Li L, Hou L. Sulfatide-containing lipid perfluorooctylbromide nanoparticles as paclitaxel vehicles targeting breast carcinoma. Int J Nanomedicine. 2014;9:397I-3985. ${ }^{33}$

Abbreviations: PFOB NPs, perfluorooctylbromide nanoparticles; PTX, paclitaxel; SNPs, sulfatide-targeted perfluorooctylbromide nanoparticles.

efficacy in preventing melanoma. Their laboratory subsequently showed that their $\alpha_{\mathrm{v}} \beta_{3}$-targeted PFOB NPs loaded with a c-Myc inhibitor prodrug extended the survival time in a mouse model of disseminated multiple myeloma. ${ }^{105}$ Song et $\mathrm{al}^{106}$ designed PFOB NPs loaded with hollow $\mathrm{Bi}_{2} \mathrm{Se}_{3}$ for the timely supply of oxygen under near-infrared irradiation to enhance cancer radiotherapy with good effectiveness. VuQuang et $\mathrm{al}^{17}$ designed multifunctional FA-targeted PFOB NPs loaded with doxorubicin in a PLGA shell and showed their good anticancer efficacy in vitro. PEGylated PFOB NPs loaded with PTX, which was dispersed in the PLGA shell of the PFOB NPs, were designed by Boissenot et $\mathrm{al}^{107}$ and produced a promising and statistically significant twofold reduction in CT-26 tumor growth compared with generic Taxol ${ }^{\circledR}$ (BristolMyers Squibb Company, Princeton, NY, USA). Angiopep-2, which is known to bind to low-density lipoprotein receptorrelated protein-1 (LRP-1), is an ideal dual-targeting moiety for a brain tumor tissue-targeted delivery system that also targets glioblastoma cells. ${ }^{108-111}$ A novel high-intensity focused US (HIFU)-responsive angiopep-2-targeted PFOB NP drug delivery system with a PLGA shell containing doxorubicin was developed by Luo et $\mathrm{al}^{112}$ to enhance the targeted therapy of glioblastoma. The rate of drug delivery was greatly increased by the application of HIFU irradiation, which enabled the PFOB NP drug delivery system to achieve the strongest efficacy against glioblastoma. ${ }^{112}$ Interestingly, the locations of the drugs (PTX or doxorubicin) in the PFOB NPs with a polymer shell for cancer therapy developed by Vu-Quang et al, ${ }^{17}$ Boissenot et $\mathrm{al}^{107}$ and Luo et $\mathrm{al}^{112}$ were ambiguous (Figure 6). Vu-Quang et $\mathrm{al}^{17}$ and Boissenot et $\mathrm{al}^{107}$ reported
A

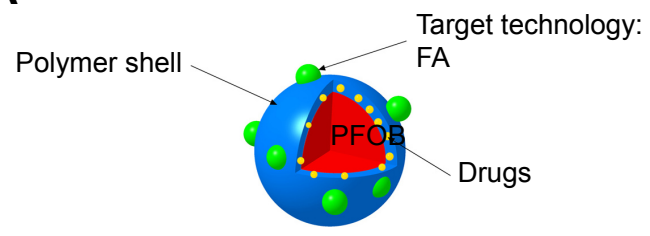

B

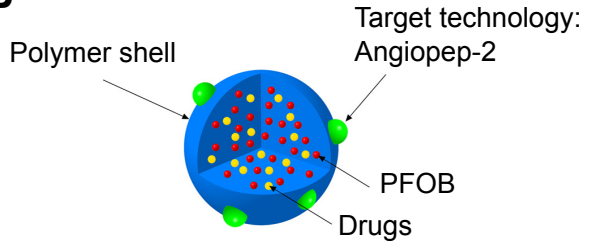

Figure 6 Schematic illustration of the location of doxorubicin or PTX in the PFOB NPs designed by Vu-Quang et $\mathrm{al}^{17}$ and Boissenot et $\mathrm{al}^{107}(\mathbf{A})$. Schematic illustration of the location of doxorubicin in the PFOB NPs designed by Luo et $\mathrm{al}^{\prime \prime 2}(\mathbf{B})$.

Abbreviations: FA, folic acid; PFOB, perfluorooctylbromide; PFOB NPs, perfluorooctylbromide nanoparticles; PTX, paclitaxel.

that the loaded drug was located in the polymer shell (Figure 6A), whereas Luo et $\mathrm{al}^{112}$ concluded that the doxorubicin used in their study was located in the center of the NPs along with PFOB (Figure 6B). For drug delivery, more studies have focused on PFOB NPs with a lipid coating than on PFOB NPs with a polymer coating. Thus, the location of the drugs in PFOB NPs with a polymer shell should be verified in further studies.

Angiogenesis is a normal physiological process required for the formation of new blood vessels from existing vessels. ${ }^{113}$ The maintenance, growth and metastasis of solid tumors also require angiogenesis, making it an attractive therapeutic target in the treatment of cancer. ${ }^{114,115}$ Biomarkers for angiogenesis, such as $\alpha_{\mathrm{v}} \beta_{3}$ integrin, vascular endothelial growth factor (VEGF), VEGF receptor-2 (VEGFR2) and $\alpha_{5} \beta_{1}$ integrin, can serve as tumor targets. ${ }^{116-119}$ In the study by Schmieder et al, ${ }^{119} \alpha_{5} \beta_{1}$-targeted PFOB NPs containing fumagillin further decreased the extent of neovessel formation but did not affect the tumor volume in an MDAMB-435 xenograft mouse model. The MDA-MB-435 tumor model exhibited a very sparse neovasculature with relatively slow growth, which may have caused the negative results. ${ }^{119}$ One molecular biosignature, $\alpha_{\mathrm{v}} \beta_{3}$ integrin, has attracted prominent attention for angiogenesis-targeted applications, because it is involved in endothelial cell recruitment and proliferation, which are important steps in the formation of new blood vessels. ${ }^{74}$ The utility of $\alpha_{v} \beta_{3}$ integrin as a biomarker of angiogenesis in cancer was studied in the VX-2 xenograft rabbit model. The $\alpha_{v} \beta_{3}$-targeted fumagillin-loaded PFOB NPs designed by Winter et $\mathrm{al}^{120}$ suppress neovasculature formation and inhibit the growth 
of VX-2 adenocarcinoma xenografts in a targeted manner. The authors subsequently combined the antiangiogenic effect of $\alpha_{v} \beta_{3}$-targeted fumagillin PFOB NPs with zoledronic acid to treat VX-2 adenocarcinoma xenografts. The dual antiangiogenic therapy decreased angiogenesis, stabilized tumor progression and enhanced the anticancer efficacy of chemotherapy. ${ }^{121}$ Pan et al ${ }^{122}$ utilized $\alpha_{v} \beta_{3}$-targeted taxane prodrug-loaded PFOB NPs to suppress neovasculature formation and inhibit the growth of VX-2 adenocarcinoma in rabbits in a targeted manner with good efficacy.

\section{Drug delivery for atherosclerosis therapy}

Atherosclerotic plaques, which progress from an early atheromatous lesion to a vulnerable plaque through aggressive inflammatory and immune responses, comprise macrophage infiltrates with necrotic core enlargement, neovascular expansion of the vasa vasorum and intraplaque hemorrhage. ${ }^{123,124}$ Angiogenesis of the vasa vasorum is required for the progression of atherosclerosis; ${ }^{125,126}$ therefore, $\alpha_{\mathrm{v}} \beta_{3}$-targeted PFOB NPs, which were mentioned earlier as an antiangiogenesis tumor therapy, also act as a vehicle for atherosclerosis therapy. Winter et al ${ }^{127}$ utilized the $\alpha_{\mathrm{v}} \beta_{3}$-targeted PFOB NPs for molecular imaging of angiogenesis in subjects with early-stage atherosclerosis and concluded that $\alpha_{v} \beta_{3}$-targeted PFOB NPs can carry several drugs in their lipid monolayers, making them an attractive candidate for drug delivery to early atherosclerotic lesions. The $\alpha_{v} \beta_{3}$-targeted PFOB NPs loaded with fumagillin prepared by Winter et $\mathrm{l}^{128}$ delivered fumagillin and elicited a marked antiangiogenic response with minimal drug dosage. Rabbits with early atherosclerotic lesions administered a single dose of $\alpha_{\mathrm{v}} \beta_{3}$-targeted fumagillin PFOB NPs displayed markedly reduced macroscopic adventitial angiogenic expansion of the vasa vasorum compared with the rabbits in the control group. ${ }^{128}$ In a subsequent study, the authors developed a prolonged antiangiogenesis therapy for atherosclerotic rabbits using atorvastatin and $\alpha_{\mathrm{v}} \beta_{3}$-targeted PFOB NPs loaded with fumagillin. The combination of atorvastatin and $\alpha_{\mathrm{v}} \beta_{3}$-targeted fumagillin-loaded PFOB NPs synergistically sustained a prolonged antiangiogenic effect in atherosclerotic rabbits. ${ }^{129}$ VCAM-1-targeted PFOB NPs were generated by Hua et al ${ }^{99}$ for targeted atherosclerosis therapy in a (ApoE-deficient) mouse model in vivo. Their results prompted subsequent studies showing that VCAM-1-targeted PFOB NPs loaded with a suitable drug are an effective targeted atherosclerosis therapy. ${ }^{99}$ The shell materials, loaded drugs and their locations and target epitopes of the PFOB NPs as a drug delivery system, which are described in the text, are summarized in Table 3.

\section{Future perspectives}

PFOB NPs are now a multifunctional nanotechnology with potential as both a drug delivery system and a diagnostic platform, and the promising results reported thus far have encouraged us to focus our attention on the following possibilities.

\section{PFOB NPs for delivering drugs while serving as diagnostic agents}

PFOB NPs offer great potential for coupling therapeutic functions with diagnostic functions, which indicates that PFOB NPs can serve as theranostic agents. ${ }^{19} \mathrm{~F}$, which is highly enriched in PFOB NPs, functions as an excellent

Table 3 Topical delivery of certain drugs using PFOB NPs as potential carriers for cancer and atherosclerosis therapies

\begin{tabular}{|c|c|c|c|c|c|}
\hline Therapy & $\begin{array}{l}\text { Shell material/ } \\
\text { loaded drug }\end{array}$ & $\begin{array}{l}\text { Target } \\
\text { epitope }\end{array}$ & $\begin{array}{l}\text { Drug } \\
\text { localization }\end{array}$ & $\begin{array}{l}\text { Drug transport } \\
\text { mechanism }\end{array}$ & References \\
\hline Loading of antitumor & Lipid/melittin & - & Lipid monolayer & Lipid exchange & 96 \\
\hline drugs for cancer & Lipid/PTX & TN-C & Lipid monolayer & Not determined & 33 \\
\hline \multirow[t]{5}{*}{ therapy } & $\begin{array}{l}\text { Lipid/c-Myc } \\
\text { inhibitor prodrug }\end{array}$ & $\alpha_{v} \beta_{3}$ integrin & Lipid monolayer & Lipid exchange & 104,105 \\
\hline & $\mathrm{Bi}_{2} \mathrm{Se}_{3} /-$ & - & - & - & 106 \\
\hline & PLGA/doxorubicin & FR & Polymer shell & No exposure & 17 \\
\hline & PLGA-PEG/PTX & - & Polymer shell & No exposure & 107 \\
\hline & PLGA/doxorubicin & LRP-I & Center of the NPs & No exposure & 112 \\
\hline Antiangiogenesis drugs & Lipid/fumagillin & $\alpha_{5} \beta_{1}$ integrin & Lipid monolayer & Lipid exchange & 119 \\
\hline \multirow[t]{2}{*}{ for cancer therapy } & Lipid/fumagillin & $\alpha_{v} \beta_{3}$ integrin & Lipid monolayer & Lipid exchange & 120,121 \\
\hline & $\begin{array}{l}\text { Lipid/taxane } \\
\text { prodrug }\end{array}$ & $\alpha_{v} \beta_{3}$ integrin & Lipid monolayer & Lipid exchange & 122 \\
\hline $\begin{array}{l}\text { Antiangiogenesis drugs } \\
\text { for atherosclerosis } \\
\text { therapy }\end{array}$ & Lipid/fumagillin & $\alpha_{v} \beta_{3}$ integrin & Lipid monolayer & Lipid exchange & 128,129 \\
\hline
\end{tabular}

Abbreviations: FR, folate receptor; LRP-I, low-density lipoprotein receptor-related protein- I; NPs, nanoparticles; PFOB NPs, perfluorooctylbromide nanoparticles; PLGA, poly(lactide-co-glycolide) acid; PLGA-PEG, poly(lactide-co-glycolide) acid-polyethylene glycol; PTX, paclitaxel; TN-C, tenascin-C. 
probe for quantitative MRI. PFOB NPs have been used to deliver drugs to a targeted site while concurrently providing direct confirmation of drug delivery and therapeutic efficacy via ${ }^{19} \mathrm{~F}$ MRI. ${ }^{130}$ A limitation for ${ }^{19} \mathrm{~F}$ MRI is the low signal from targeted/localized PFOB NPs. Thus, PFOB NPs have been modified with payloads of paramagnetic chelates (eg, Gd-DTPA) for high-resolution diagnostic imaging and have been integrated with therapeutic agents for antiangiogenesis therapy. ${ }^{77,120,128,129,131,132}$

In the clinic, two or more biomedical imaging techniques are usually applied together to achieve more reliable diagnostic results, as each imaging technique has its specific advantages and limitations. ${ }^{58}$ Hyaluronic acid, a biocompatible and biodegradable material utilized in the development of various drug delivery systems, has also been widely used in the design and fabrication of drug conjugates and NPs for therapy. ${ }^{133}$ Near-infrared dye-conjugated hyaluronic acid-encapsulating PFOB NPs represent another approach to realize the theranostics: the unique properties of PFOB NPs as contrast agents were enhanced by the coating agents to which they had been conjugated, endowing them with fluorescence in near-infrared imaging and cancer cell-tracking capabilities due to their interaction with hyaluronidases. ${ }^{134,135}$ Multifunctional UCAs designed by coating the outside of PFOB NPs with hyaluronic acid certainly have potential as theranostic agents for applications in which two or more biomedical imaging techniques are applied together.

\section{PFOB NPs for delivering drugs while serving as diagnostic agents via ultrasonography}

As a multifunctional nanotechnology, PFOB NPs have been evaluated for use in various medical applications. In contrast to $\mathrm{CT} / \mathrm{MRI}$, US imaging is a more cost-effective and accessible imaging technique and does not use ionizing radiation. ${ }^{136}$ Nevertheless, the question remains: how do we design PFOB NPs to achieve therapeutic functions coupled with diagnostic functions via ultrasonography?

Importantly, in recent years, two laboratories ${ }^{63,72}$ have designed targeted PFOB NPs that successfully enhanced tumor US imaging in vivo. The most recently reported success in the application of targeted PFOB NPs with a lipid coating to targeted US imaging has inspired a substantial number of subsequent studies on achieving therapeutic functions coupled with diagnostic functions via ultrasonography. The capacity to enhance US imaging will be tremendously improved by developing targeted PFOB NPs to enhance US imaging of the site of interest ${ }^{63,72}$ however, there is still no study on the use of PFOB NPs to deliver drugs while serving as diagnostic agents for ultrasonography in vivo. The accumulation of targeted PFOB NPs within the target tissue at a level that is not sufficient to achieve high-quality US imaging enhancement remains a challenge for subsequent studies in this area. Although a single ligand might improve the tumor-targeted US imaging to some extent, the Arg-GlyAsp- ${ }^{63}$ or FA-modified ${ }^{72}$ PFOB NPs may not be sufficient to target tumor tissue for higher-quality tumor US imaging. Therefore, additional targeting strategies should be applied to improve the targeting ability of PFOB NPs with a lipid coating. We predict that to address this need, researchers will introduce various biological ligands into PFOB NPs as part of a novel dual-targeting concept, which may provide them with an opportunity to obtain higher-quality tumor US images. This novel dual-targeting concept has already improved the selective delivery of drugs to tumor tissues ${ }^{137}$ and is anticipated to facilitate the use of PFOB NPs to further improve tumor US imaging and to achieve the goal of delivering drugs while serving as diagnostic agents for ultrasonography in vivo in the future.

In addition, to extend their applications, PFOB NPs must exhibit minimal toxicity. Recent studies have shown that cell fate can be dictated by the stiffness and topographical characteristics of the ECM. ${ }^{138}$ Thus, the cellular uptake of NPs can also be regulated, which would influence the efficacy and toxicity of these nanomaterials. Through optimization of the shape and dimensions, particularly the height of nanotopography, the nuclear volume can be modulated through focal adhesion rearrangement to regulate cell function for the end application. ${ }^{139-141}$ Thus, delineation of the relationships between cell adhesion and nucleus and cell function may provide insight into the rational design of PFOB NPs as novel theranostic agents.

\section{Conclusion}

Our laboratory and many other groups have reported that PFOB NPs are a useful system for the delivery of therapeutic agents to target tissues with good efficacy. For drug delivery, more studies have focused on PFOB NPs with a lipid coating than on PFOB NPs with a polymer coating. In summary, we conclude that PFOB NPs, particularly PFOB NPs with a lipid coating, can serve as an effective drug delivery carrier for cancer and atherosclerosis therapies.

Although PFOB NPs are capable of increasing the visualization of US imaging and have been extensively studied, the pace of their development has been relatively slow. Sensitive US imaging will benefit from the optimization 
of ultrasonography parameters, formulations and targeting abilities, as this nascent application still requires additional efforts. Polymer-coated PFOB NPs have been studied more frequently to optimize ultrasonography parameters and develop formulations for pool imaging in vivo, whereas lipid-coated PFOB NPs can be functionalized with specific ligands and have been studied for targeted tumor ultrasound imaging in vivo.

With a diverse portfolio of therapeutic and potential diagnostic functions via ultrasonography, PFOB NPs may play a promising role in many of the cutting-edge technologies that are currently being developed to fight the most pressing challenges facing the field of medicine today.

\section{Disclosure}

The authors report no conflicts of interest in this work.

\section{References}

1. Giraudeau C, Geffroy F, Meriaux S, et al. 19F molecular MR imaging for detection of brain tumor angiogenesis: in vivo validation using targeted PFOB nanoparticles. Angiogenesis. 2013;16(1):171-179.

2. Wolfson MR, Greenspan JS, Shaffer TH. Liquid-assisted ventilation: an alternative respiratory modality. Pediatr Pulmonol. 1998;26(1):42-63.

3. Obraztsov VV, Grishanova A, Shekhtman DG, Sklifas AN, Makarov KN. [Interaction of perfluoroctylbromide with liver microsomal monooxygenase]. Biokhimiia. 1993;58(8):1234-1239.

4. Long DM, Long DC, Mattrey RF, et al. An overview of perfluoroctylbromide - application as a synthetic oxygen carrier and imaging agent for X-ray, ultrasound and nuclear magnetic resonance. Biomater Artif Cells Artif Organs. 1988;16(1-3):411-420.

5. Ellena JF, Obraztsov VV, Cumbea VL, Woods CM, Cafiso DS. Perfluorooctyl bromide has limited membrane solubility and is located at the bilayer center. Locating small molecules in lipid bilayers through paramagnetic enhancements of NMR relaxation. J Med Chem. 2002; 45(25):5534-5542.

6. Krafft MP. Fluorocarbons and fluorinated amphiphiles in drug delivery and biomedical research. Adv Drug Deliver Rev. 2001;47(2-3): 209-228.

7. Wang K, Huang Q, Qiu F, Sui M. Non-viral delivery systems for the application in p53 cancer gene therapy. Curr Med Chem. 2015;22(35): 4118-4136.

8. Zhang B, Wang K, Si J, Sui M, Shen Y. Charge-reversal polymers for biodelivery. In: Gu Z, editor. Bioinspired and Biomimetic Polymer Systems for Drug and Gene Delivery. Weinheim, Germany: Wiley-VCH Verlag GmbH \& Co. KGaA; 2014:223-242.

9. Pisani E, Tsapis N, Galaz B, Bridal SL, Fattal E. Perfluorooctyl bromide polymeric capsules as dual contrast agents for ultrasonography and magnetic resonance imaging. Adv Funct Mater. 2008;18(19):2963-2971.

10. Wakabayashi T, Tamura M, Nakamura T. Partial liquid ventilation with low-dose perfluorochemical and high-frequency oscillation improves oxygenation and lung compliance in a rabbit model of surfactant depletion. Biol Neonate. 2006;89(3):177-182.

11. Riess JG. Perfluorocarbon-based oxygen delivery. Artif Cells Blood Substit Immobil Biotechnol. 2006;34(6):567-580.

12. Jacoby C, Temme S, Mayenfels F, et al. Probing different perfluorocarbons for in vivo inflammation imaging by 19F MRI: image reconstruction, biological half-lives and sensitivity. NMR Biomed. 2014;27(3): 261-271.

13. Goette MJ, Keupp J, Rahmer J, Lanza GM, Wickline SA, Caruthers SD. Balanced UTE-SSFP for 19F MR imaging of complex spectra. Magn Reson Med. 2015;74(2):537-543.
14. Schmieder AH, Wang K, Zhang $\mathrm{H}$, et al. Characterization of early neovascular response to acute lung ischemia using simultaneous (19) F/(1)H MR molecular imaging. Angiogenesis. 2014;17(1):51-60.

15. Morawski AM, Winter PM, Yu X, et al. Quantitative "magnetic resonance immunohistochemistry" with ligand-targeted (19)F nanoparticles. Magn Reson Med. 2004;52(6):1255-1262.

16. Waters EA, Chen J, Yang X, et al. Detection of targeted perfluorocarbon nanoparticle binding using 19F diffusion weighted MR spectroscopy. Magn Reson Med. 2008;60(5):1232-1236.

17. Vu-Quang H, Vinding MS, Nielsen T, Ullisch MG, Nielsen NC, Kjems J. Theranostic tumor targeted nanoparticles combining drug delivery with dual near infrared and $19 \mathrm{~F}$ magnetic resonance imaging modalities. Nanomedicine. 2016;12(7):1873-1884.

18. Giraudeau C, Djemai B, Ghaly MA, et al. High sensitivity 19F MRI of a perfluorooctyl bromide emulsion: application to a dynamic biodistribution study and oxygen tension mapping in the mouse liver and spleen. NMR Biomed. 2012;25(4):654-660.

19. Diou O, Tsapis N, Giraudeau C, et al. Long-circulating perfluorooctyl bromide nanocapsules for tumor imaging by 19FMRI. Biomaterials. 2012;33(22):5593-5602.

20. Partlow KC, Chen J, Brant JA, et al. 19F magnetic resonance imaging for stem/progenitor cell tracking with multiple unique perfluorocarbon nanobeacons. FASEB J. 2007;21(8):1647-1654.

21. Barnett BP, Ruiz-Cabello J, Hota P, et al. Use of perfluorocarbon nanoparticles for non-invasive multimodal cell tracking of human pancreatic islets. Mol Imaging. 2011;6(4):251-259.

22. Ahrens ET, Flores R, Xu H, Morel PA. In vivo imaging platform for tracking immunotherapeutic cells. Nat Biotechnol. 2005;23(8):983-987.

23. Hill ML, Gorelikov I, Niroui F, et al. Towards a nanoscale mammographic contrast agent: development of a modular pre-clinical dual optical/x-ray agent. Phys Med Biol. 2013;58(15):5215-5235.

24. Mattrey RF, Brown JJ, Shelton RE, Ogino MT, Johnson KK, Mitten RM. Use of perfluorooctylbromide (PFOB) to detect liver abscesses with computed tomography. Safety and efficacy. Invest Radiol. 1991;26(9): 792-798.

25. Liu Z, Lammers T, Ehling J, et al. Iron oxide nanoparticle-containing microbubble composites as contrast agents for MR and ultrasound dual-modality imaging. Biomaterials. 2011;32(26):6155-6163.

26. Mattrey RF, Scheible FW, Gosink BB, Leopold GR, Long DM, Higgins CB. Perfluoroctylbromide: a liver/spleen-specific and tumorimaging ultrasound contrast material. Radiology. 1982;145(3):759-762.

27. Lanza GM, Wallace KD, Scott MJ, et al. A novel site-targeted ultrasonic contrast agent with broad biomedical application. Circulation. 1996;94(12):3334-3340.

28. Jafari S, Diou O, Mamou J, et al. High-frequency (20 to $40 \mathrm{MHz}$ ) acoustic response of liquid-filled nanocapsules. IEEE Trans Ultrason Ferroelectr Freq Control. 2014;61(1):5-15.

29. Marsh JN, Hall CS, Scott MJ, et al. Improvements in the ultrasonic contrast of targeted perfluorocarbon nanoparticles using an acoustic transmission line model. IEEE Trans Ultrason Ferroelectr Freq Control. 2002;49(1):29-38.

30. Wickline SA, Hughes M, Ngo FC, et al. Blood contrast enhancement with a novel, non-gaseous nanoparticle contrast agent. Acad Radiol. 2002;9(suppl 2):S290-S293.

31. Diaz-Lopez R, Tsapis N, Fattal E. Liquid perfluorocarbons as contrast agents for ultrasonography and (19)F-MRI. Pharm Res. 2010; 27(1):1-16.

32. Zhou HF, Chan HW, Wickline SA, Lanza GM, Pham CT. Alphavbeta3targeted nanotherapy suppresses inflammatory arthritis in mice. FASEB J. 2009;23(9):2978-2985.

33. Li X, Qin F, Yang L, Mo L, Li L, Hou L. Sulfatide-containing lipid perfluorooctylbromide nanoparticles as paclitaxel vehicles targeting breast carcinoma. Int J Nanomedicine. 2014;9:3971-3985.

34. Morawski AM, Winter PM, Crowder KC, et al. Targeted nanoparticles for quantitative imaging of sparse molecular epitopes with MRI. Magn Reson Med. 2004;51(3):480-486.

35. Rossi M. Use of lecithin and lecithin fractions. In BioactiVe Egg Compounds. 2007;3(4):229-239. 
36. Keipert PE, Otto S, Flaim SF, et al. Influence of perflubron emulsion particle size on blood half-life and febrile response in rats. Artif Cells Blood Substit Immobil Biotechnol. 1994;22(4):1169-1174.

37. Diaz-Lopez R, Tsapis N, Libong D, et al. Phospholipid decoration of microcapsules containing perfluorooctyl bromide used as ultrasound contrast agents. Biomaterials. 2009;30(8):1462-1472.

38. Diaz-Lopez R, Libong D, Tsapis N, Fattal E, Chaminade P. Quantification of pegylated phospholipids decorating polymeric microcapsules of perfluorooctyl bromide by reverse phase HPLC with a charged aerosol detector. J Pharm Biomed Anal. 2008;48(3):702-707.

39. Ke H, Yue X, Wang J, et al. Gold nanoshelled liquid perfluorocarbon nanocapsules for combined dual modal ultrasound/CT imaging and photothermal therapy of cancer. Small. 2014;10(6):1220-1227.

40. Flegg MB, Poole CM, Whittaker AK, Keen I, Langton CM. Rayleigh theory of ultrasound scattering applied to liquid-filled contrast nanoparticles. Phys Med Biol. 2010;55(11):3061-3076.

41. Pisani E, Fattal E, Paris J, Ringard C, Rosilio V, Tsapis N. Surfactant dependent morphology of polymeric capsules of perfluorooctyl bromide: influence of polymer adsorption at the dichloromethane-water interface. J Colloid Interface Sci. 2008;326(1):66-71.

42. Makadia HK, Siegel SJ. Poly lactic-co-glycolic acid (PLGA) as biodegradable controlled drug delivery carrier. Polymers (Basel). 2011;3(3): 1377-1397.

43. Shive MS, Anderson JM. Biodegradation and biocompatibility of PLA and PLGA microspheres. Adv Drug Deliv Rev. 1997;28(1):5-24.

44. Li H, Wang P, Wang X, et al. Perfluorooctyl bromide traces selfassembled with polymeric nanovesicles for blood pool ultrasound imaging. Biomater Sci. 2016;4(6):979-988.

45. Podell S, Burrascano C, Gaal M, Golec B, Maniquis J, Mehlhaff P. Physical and biochemical stability of Optison, an injectable ultrasound contrast agent. Biotechnol Appl Biochem. 1999;30(pt 3):213-223.

46. Kitzman DW, Goldman ME, Gillam LD, Cohen JL, Aurigemma GP, Gottdiener JS. Efficacy and safety of the novel ultrasound contrast agent perflutren (definity) in patients with suboptimal baseline left ventricular echocardiographic images. Am J Cardiol. 2000;86(6): 669-674.

47. Yuan F, Dellian M, Fukumura D, et al. Vascular permeability in a human tumor xenograft: molecular size dependence and cutoff size. Cancer Res 1995;55(17):3752-3756.

48. Hughes MS, Marsh JN, Hall CS, et al. Acoustic characterization in whole blood and plasma of site-targeted nanoparticle ultrasound contrast agent for molecular imaging. J Acoust Soc Am. 2005;117(2): 964-972.

49. Foster FS, Pavlin CJ, Harasiewicz KA, Christopher DA, Turnbull DH. Advances in ultrasound biomicroscopy. Ultrasound Med Biol. 2000; 26(1):1-27.

50. Foster FS, Zhang MY, Zhou YQ, et al. A new ultrasound instrument for in vivo microimaging of mice. Ultrasound Med Biol. 2002;28(9): 1165-1172.

51. Mor-Avi V, Lang RM. Recent advances in echocardiographic evaluation of left ventricular anatomy, perfusion, and function. Cardiol Rev. 2001;9(3):146-159.

52. Li Z, Ke H, Wang J, Miao Z, Yue X. Graphene oxide and gadoliniumchelate functionalized poly(lactic acid) nanocapsules encapsulating perfluorooctylbromide for ultrasound/magnetic resonance bimodal imaging guided photothermal ablation of cancer. J Nanosci Nanotechnol. 2016;16(3):2201-2209.

53. Pisani E, Tsapis N, Paris J, Nicolas V, Cattel L, Fattal E. Polymeric nano/microcapsules of liquid perfluorocarbons for ultrasonic imaging physical characterization. Langmuir. 2006;22(9):4397-4402.

54. Diou O, Brulet A, Pehau-Arnaudet G, et al. PEGylated nanocapsules of perfluorooctyl bromide: mechanism of formation, influence of polymer concentration on morphology and mechanical properties. Colloids Surf B Biointerfaces. 2016;146:762-769.

55. Haiat G, Berti R, Galaz B, Taulier N, Amman JJ, Urbach W. Twodimensional simulation of linear wave propagation in a suspension of polymeric microcapsules used as ultrasound contrast agents. J Acoust Soc Am. 2011;129(3):1642-1652.
56. Barnett BP, Ruiz-Cabello J, Hota P, et al. Fluorocapsules for improved function, immunoprotection, and visualization of cellular therapeutics with MR, US, and CT imaging. Radiology. 2011;258(1):182-191.

57. Zha Z, Wang J, Zhang S, et al. Engineering of perfluorooctylbromide polypyrrole nano-/microcapsules for simultaneous contrast enhanced ultrasound imaging and photothermal treatment of cancer. Biomaterials. 2014;35(1):287-293.

58. Ke H, Wang J, Tong S, et al. Gold nanoshelled liquid perfluorocarbon magnetic nanocapsules: a nanotheranostic platform for bimodal ultrasound/magnetic resonance imaging guided photothermal tumor ablation. Theranostics. 2013;4(1):12-23.

59. Li A, Zheng Y, Yu J, et al. Superparamagnetic perfluorooctylbromide nanoparticles as a multimodal contrast agent for US, MR, and CT imaging. Acta Radiol. 2013;54(3):278-283.

60. Nolte I, Vince GH, Maurer M, et al. Iron particles enhance visualization of experimental gliomas with high-resolution sonography. AJNR Am J Neuroradiol. 2005;26(6):1469-1474.

61. Marsh JN, Partlow KC, Abendschein DR, Scott MJ, Lanza GM, Wickline SA. Molecular imaging with targeted perfluorocarbon nanoparticles: quantification of the concentration dependence of contrast enhancement for binding to sparse cellular epitopes. Ultrasound Med Biol. 2007;33(6):950-958.

62. Kobayashi H, Turkbey B, Watanabe R, Choyke PL. Cancer drug delivery: considerations in the rational design of nanosized bioconjugates. Bioconjug Chem. 2014;25(12):2093-2100.

63. Hughes MS, Marsh JN, Arbeit JM, et al. Application of Renyi entropy for ultrasonic molecular imaging. J Acoust Soc Am. 2009;125(5): 3141-3145.

64. Diaz-Lopez R, Tsapis N, Santin M, et al. The performance of PEGylated nanocapsules of perfluorooctyl bromide as an ultrasound contrast agent. Biomaterials. 2010;31(7):1723-1731.

65. Zhao R, Matherly LH, Goldman ID. Membrane transporters and folate homeostasis: intestinal absorption and transport into systemic compartments and tissues. Expert Rev Mol Med. 2009;11:e4.

66. Kane MA. The role of folates in squamous cell carcinoma of the head and neck. Cancer Detect Prev. 2005;29(1):46-53.

67. Hartmann LC, Keeney GL, Lingle WL, et al. Folate receptor overexpression is associated with poor outcome in breast cancer. Int J Cancer. 2007;121(5):938-942.

68. O’Shannessy DJ, Yu G, Smale R, et al. Folate receptor alpha expression in lung cancer: diagnostic and prognostic significance. Oncotarget. 2012; 3(4):414-425.

69. Parker N, Turk MJ, Westrick E, Lewis JD, Low PS, Leamon CP. Folate receptor expression in carcinomas and normal tissues determined by a quantitative radioligand binding assay. Anal Biochem. 2005;338(2): 284-293.

70. Assaraf YG, Leamon CP, Reddy JA. The folate receptor as a rational therapeutic target for personalized cancer treatment. Drug Resist Updat. 2014;17(4-6):89-95.

71. Hu Y, Wang Y, Jiang J, et al. Preparation and characterization of novel perfluorooctyl bromide nanoparticle as ultrasound contrast agent via layer-by-layer self-assembly for folate-receptor-mediated tumor imaging. Biomed Res Int. 2016;2016:6381464.

72. Li K, Liu Y, Zhang S, et al. Folate receptor-targeted ultrasonic PFOB nanoparticles: synthesis, characterization and application in tumortargeted imaging. Int J Mol Med. 2017;39(6):1505-1515.

73. Tran TD, Caruthers SD, Hughes M, et al. Clinical applications of perfluorocarbon nanoparticles for molecular imaging and targeted therapeutics. Int J Nanomedicine. 2007;2(4):515-526.

74. Winter PM. Perfluorocarbon nanoparticles: evolution of a multimodality and multifunctional imaging agent. Scientifica (Cairo). 2014; 2014:746574.

75. Castro CI, Briceno JC. Perfluorocarbon-based oxygen carriers: review of products and trials. Artif Organs. 2010;34(8):622-634.

76. Kaneda MM, Sasaki Y, Lanza GM, Milbrandt J, Wickline SA. Mechanisms of nucleotide trafficking during siRNA delivery to endothelial cells using perfluorocarbon nanoemulsions. Biomaterials. 2010;31(11): 3079-3086. 
77. Lanza GM, Yu X, Winter PM, et al. Targeted antiproliferative drug delivery to vascular smooth muscle cells with a magnetic resonance imaging nanoparticle contrast agent: implications for rational therapy of restenosis. Circulation. 2002;106(22):2842-2847.

78. Lee SJ, Schlesinger PH, Wickline SA, Lanza GM, Baker NA. Interaction of melittin peptides with perfluorocarbon nanoemulsion particles. J Phys Chem B. 2011;115(51):15271-15279.

79. Pan D, Pham CT, Weilbaecher KN, Tomasson MH, Wickline SA, Lanza GM. Contact-facilitated drug delivery with Sn2 lipase labile prodrugs optimize targeted lipid nanoparticle drug delivery. Wiley Interdiscip Rev Nanomed Nanobiotechnol. 2016;8(1):85-106.

80. Lee SJ, Schlesinger PH, Wickline SA, Lanza GM, Baker NA. Simulation of fusion-mediated nanoemulsion interactions with model lipid bilayers. Soft Matter. 2012;8(26):3024-3035.

81. Zhou HF, Hu G, Wickline SA, Lanza GM, Pham CT. Synergistic effect of antiangiogenic nanotherapy combined with methotrexate in the treatment of experimental inflammatory arthritis. Nanomedicine (Lond). 2010;5(7):1065-1074.

82. Zhou HF, Yan H, Senpan A, et al. Suppression of inflammation in a mouse model of rheumatoid arthritis using targeted lipase-labile fumagillin prodrug nanoparticles. Biomaterials. 2012;33(33):8632-8640.

83. Tomlinson RE, McKenzie JA, Schmieder AH, Wohl GR, Lanza GM, Silva MJ. Angiogenesis is required for stress fracture healing in rats. Bone. 2013;52(1):212-219.

84. Tomlinson RE, Schmieder AH, Quirk JD, Lanza GM, Silva MJ. Antagonizing the alphav beta3 integrin inhibits angiogenesis and impairs woven but not lamellar bone formation induced by mechanical loading. J Bone Mine Res. 2014;29(9):1970-1980.

85. Lanza GM, Jenkins J, Schmieder AH, et al. Anti-angiogenic nanotherapy inhibits airway remodeling and hyper-responsiveness of dust mite triggered asthma in the Brown Norway rat. Theranostics. 2017;7(2): 377-389.

86. Jallouk AP, Moley KH, Omurtag K, et al. Nanoparticle incorporation of melittin reduces sperm and vaginal epithelium cytotoxicity. PLoS One. 2014;9(4):e95411.

87. Pham CT, Thomas DG, Beiser J, et al. Application of a hemolysis assay for analysis of complement activation by perfluorocarbon nanoparticles. Nanomedicine. 2014;10(3):651-660.

88. Marsh JN, Senpan A, Hu G, et al. Fibrin-targeted perfluorocarbon nanoparticles for targeted thrombolysis. Nanomedicine (Lond). 2007; 2(4):533-543.

89. Marsh JN, Hu G, Scott MJ, et al. A fibrin-specific thrombolytic nanomedicine approach to acute ischemic stroke. Nanomedicine (Lond). 2011;6(4):605-615.

90. Cyrus T, Zhang H, Allen JS, et al. Intramural delivery of rapamycin with alphavbeta3-targeted paramagnetic nanoparticles inhibits stenos is after balloon injury. Arterioscler Thromb Vasc Biol. 2008;28(5): $820-826$.

91. Wong HL, Bendayan R, Rauth AM, Li Y, Wu XY. Chemotherapy with anticancer drugs encapsulated in solid lipid nanoparticles. Adv Drug Deliv Rev. 2007;59(6):491-504.

92. Din FU, Aman W, Ullah I, et al. Effective use of nanocarriers as drug delivery systems for the treatment of selected tumors. Int JNanomedicine. 2017;12:7291-7309.

93. Wang H, Lu Z, Wang L, et al. New generation nanomedicines constructed from self-assembling small molecule prodrugs alleviate cancer drug toxicity. Cancer Res. 2017;77(24):6963-6974.

94. Mishra B, Patel BB, Tiwari S. Colloidal nanocarriers: a review on formulation technology, types and applications toward targeted drug delivery. Nanomedicine. 2010;6(1):9-24.

95. How CW, Rasedee A, Manickam S, Rosli R. Tamoxifen-loaded nanostructured lipid carrier as a drug delivery system: characterization, stability assessment and cytotoxicity. Colloids Surf B Biointerfaces. 2013;112:393-399.

96. Soman NR, Baldwin SL, Hu G, et al. Molecularly targeted nanocarriers deliver the cytolytic peptide melittin specifically to tumor cells in mice, reducing tumor growth. J Clin Invest. 2009;119(9):2830-2842.
97. Frechou M, Beray-Berthat V, Raynaud JS, et al. Detection of vascular cell adhesion molecule-1 expression with USPIO-enhanced molecular MRI in a mouse model of cerebral ischemia. Contrast Media Mol Imaging. 2013;8(2):157-164.

98. Burtea C, Ballet S, Laurent S, et al. Development of a magnetic resonance imaging protocol for the characterization of atherosclerotic plaque by using vascular cell adhesion molecule-1 and apoptosis-targeted ultrasmall superparamagnetic iron oxide derivatives. Arterioscler Thromb Vasc Biol. 2012;32(6):e36-e48.

99. Pan H, Myerson JW, Hu L, et al. Programmable nanoparticle functionalization for in vivo targeting. FASEB J. 2013;27(1):255-264.

100. Galkina E, Ley K. Vascular adhesion molecules in atherosclerosis. Arterioscler Thromb Vasc Biol. 2007;27(11):2292-2301.

101. O'Hanlon DM, Fitzsimons H, Lynch J, Tormey S, Malone C, Given HF. Soluble adhesion molecules (E-selectin, ICAM-1 and VCAM-1) in breast carcinoma. Eur J Cancer. 2002;38(17):2252-2257.

102. Crossin KL, Edelman GM. Specific binding of cytotactin to sulfated glycolipids. J Neurosci Res. 1992;33(4):631-638.

103. Chiquet-Ehrismann R, Chiquet M. Tenascins: regulation and putative functions during pathological stress. J Pathol. 2003;200(4):488-499.

104. Pan D, Kim B, Hu G, et al. A strategy for combating melanoma with oncogenic c-Myc inhibitors and targeted nanotherapy. Nanomedicine (Lond). 2015;10(2):241-251.

105. Soodgupta D, Pan D, Cui G, et al. Small molecule MYC inhibitor conjugated to integrin-targeted nanoparticles extends survival in a mouse model of disseminated multiple myeloma. Mol Cancer Ther. 2015;14(6):1286-1294.

106. Song G, Liang C, Yi X, et al. Perfluorocarbon-loaded hollow Bi2Se3 nanoparticles for timely supply of oxygen under near-infrared light to enhance the radiotherapy of cancer. Adv Mater. 2016;28(14): 2716-2723.

107. Boissenot T, Fattal E, Bordat A, et al. Paclitaxel-loaded PEGylated nanocapsules of perfluorooctyl bromide as theranostic agents. Eur $J$ Pharm Biopharm. 2016;108:136-144.

108. Shao K, Huang R, Li J, et al. Angiopep-2 modified PE-PEG based polymeric micelles for amphotericin B delivery targeted to the brain. J Control Release. 2010;147(1):118-126.

109. Ruan S, Yuan M, Zhang L, et al. Tumor microenvironment sensitive doxorubicin delivery and release to glioma using angiopep-2 decorated gold nanoparticles. Biomaterials. 2015;37:425-435.

110. Huang S, Li J, Han L, et al. Dual targeting effect of Angiopep-2modified, DNA-loaded nanoparticles for glioma. Biomaterials. 2011;32(28):6832-6838.

111. Xin H, Jiang X, Gu J, et al. Angiopep-conjugated poly(ethylene glycol)-co-poly(epsilon-caprolactone) nanoparticles as dual-targeting drug delivery system for brain glioma. Biomaterials. 2011;32(18): 4293-4305.

112. Luo Z, Jin K, Pang Q, et al. On-demand drug release from dualtargeting small nanoparticles triggered by high-intensity focused ultrasound enhanced glioblastoma-targeting therapy. ACS Appl Mater Interfaces. 2017;9(37):31612-31625.

113. Adams RH, Alitalo K. Molecular regulation of angiogenesis and lymphangiogenesis. Nat Rev Mol Cell Biol. 2007;8(6):464-478.

114. Li JL, Harris AL. Crosstalk of VEGF and Notch pathways in tumour angiogenesis: therapeutic implications. Front Biosci. 2009;14: 3094-3110.

115. Folkman J. Angiogenesis and apoptosis. Semin Cancer Biol. 2003; 13(2):159-167.

116. Kooiman K, Foppen-Harteveld M, van der Steen AF, de Jong N. Sonoporation of endothelial cells by vibrating targeted microbubbles. J Control Release. 2011;154(1):35-41.

117. Kiessling F, Fokong S, Bzyl J, Lederle W, Palmowski M, Lammers T. Recent advances in molecular, multimodal and theranostic ultrasound imaging. Adv Drug Deliv Rev. 2014;72:15-27.

118. Pochon S, Tardy I, Bussat P, et al. BR55: a lipopeptide-based VEGFR2-targeted ultrasound contrast agent for molecular imaging of angiogenesis. Invest Radiol. 2010;45(2):89-95. 
119. Schmieder AH, Caruthers SD, Zhang H, et al. Three-dimensional MR mapping of angiogenesis with alpha5beta1(alpha nu beta3)-targeted theranostic nanoparticles in the MDA-MB-435 xenograft mouse model. FASEB J. 2008;22(12):4179-4189.

120. Winter PM, Schmieder AH, Caruthers SD, et al. Minute dosages of alpha(nu)beta3-targeted fumagillin nanoparticles impair $\mathrm{Vx}-2$ tumor angiogenesis and development in rabbits. FASEB J. 2008;22(8): 2758-2767.

121. Esser AK, Schmieder AH, Ross MH, et al. Dual-therapy with alphavbeta3-targeted Sn2 lipase-labile fumagillin-prodrug nanoparticles and zoledronic acid in the $\mathrm{Vx} 2$ rabbit tumor model. Nanomedicine. 2016;12(1):201-211.

122. Pan D, Schmieder AH, Wang K, et al. Anti-angiogenesis therapy in the Vx2 rabbit cancer model with a lipase-cleavable Sn 2 taxane phospholipid prodrug using alpha(v)beta(3)-targeted theranostic nanoparticles. Theranostics. 2014;4(6):565-578.

123. Moreno PR, Purushothaman KR, Fuster V, et al. Plaque neovascularization is increased in ruptured atherosclerotic lesions of human aorta: implications for plaque vulnerability. Circulation. 2004;110(14): 2032-2038.

124. Moreno PR, Purushothaman KR, Sirol M, Levy AP, Fuster V. Neovascularization in human atherosclerosis. Circulation. 2006;113(18): $2245-2252$

125. McCarthy MJ, Loftus IM, Thompson MM, et al. Angiogenesis and the atherosclerotic carotid plaque: an association between symptomatology and plaque morphology. J Vasc Surg. 1999;30(2):261-268.

126. Jain RK, Finn AV, Kolodgie FD, Gold HK, Virmani R. Antiangiogenic therapy for normalization of atherosclerotic plaque vasculature: a potential strategy for plaque stabilization. Nat Clin Pract Cardiovasc Med. 2007;4(9):491-502.

127. Winter PM, Morawski AM, Caruthers SD, et al. Molecular imaging of angiogenesis in early-stage atherosclerosis with alpha(v)beta3-integrintargeted nanoparticles. Circulation. 2003;108(18):2270-2274.

128. Winter PM, Neubauer AM, Caruthers SD, et al. Endothelial alpha(v) beta3 integrin-targeted fumagillin nanoparticles inhibit angiogenesis in atherosclerosis. Arterioscler Thromb Vasc Biol. 2006;26(9): 2103-2109.

129. Winter PM, Caruthers SD, Zhang H, Williams TA, Wickline SA, Lanza GM. Antiangiogenic synergism of integrin-targeted fumagillin nanoparticles and atorvastatin in atherosclerosis. JACC Cardiovasc Imaging. 2008;1(5):624-634.
130. Kaneda MM, Caruthers S, Lanza GM, Wickline SA. Perfluorocarbon nanoemulsions for quantitative molecular imaging and targeted therapeutics. Ann Biomed Eng. 2009;37(10):1922-1933.

131. Schmieder AH, Winter PM, Caruthers SD, et al. Molecular MR imaging of melanoma angiogenesis with alphanubeta3-targeted paramagnetic nanoparticles. Magn Reson Med. 2005;53(3):621-627.

132. Winter PM, Caruthers SD, Kassner A, et al. Molecular imaging of angiogenesis in nascent $\mathrm{Vx}-2$ rabbit tumors using a novel alpha(nu) beta3-targeted nanoparticle and 1.5 tesla magnetic resonance imaging. Cancer Res. 2003;63(18):5838-5843.

133. Ganau M, Syrmos NC, D'Arco F, et al. Enhancing contrast agents and radiotracers performance through hyaluronic acid-coating in neuroradiology and nuclear medicine. Hell J Nucl Med. 2017;20(2):166-168.

134. Liang X, Fang L, Li X, Zhang X, Wang F. Activatable near infrared dye conjugated hyaluronic acid based nanoparticles as a targeted theranostic agent for enhanced fluorescence/CT/photoacoustic imaging guided photothermal therapy. Biomaterials. 2017;132:72-84.

135. Ganau M. Tackling gliomas with nanoformulated antineoplastic drugs: suitability of hyaluronic acid nanoparticles. Clin Transl Oncol. 2014; 16(2):220-223

136. Rapoport N. Phase-shift, stimuli-responsive perfluorocarbon nanodroplets for drug delivery to cancer. Wiley Interdiscip Rev Nanomed Nanobiotechnol. 2012;4(5):492-510.

137. Ke X, Lin W, Li X, Wang H, Xiao X, Guo Z. Synergistic dual-modified liposome improves targeting and therapeutic efficacy of bone metastasis from breast cancer. Drug Deliv. 2017;24(1):1680-1689.

138. Yang Y, Wang K, Gu X, Leong KW. Biophysical regulation of cell behavior-cross talk between substrate stiffness and nanotopography. Engineering (Beijing). 2017;3(1):36-54

139. Wang K, He X, Linthicum W, et al. Carbon nanotubes induced fibrogenesis on nanostructured substrates. Environ Sci Nano. 2017;4(3): 689-699.

140. Wang K, Bruce A, Mezan R, et al. Nanotopographical modulation of cell function through nuclear deformation. ACS Appl Mater Interfaces. 2016;8(8):5082-5092.

141. Song L, Wang K, Li Y, Yang Y. Nanotopography promoted neuronal differentiation of human induced pluripotent stem cells. Colloids Surf B Biointerfaces. 2016;148:49-58.
International Journal of Nanomedicine

\section{Publish your work in this journal}

The International Journal of Nanomedicine is an international, peerreviewed journal focusing on the application of nanotechnology in diagnostics, therapeutics, and drug delivery systems throughout the biomedical field. This journal is indexed on PubMed Central, MedLine, CAS, SciSearch $®$, Current Contents $\AA /$ Clinical Medicine,

\section{Dovepress}

Journal Citation Reports/Science Edition, EMBase, Scopus and the Elsevier Bibliographic databases. The manuscript management system is completely online and includes a very quick and fair peer-review system, which is all easy to use. Visit http://www.dovepress.com/ testimonials.php to read real quotes from published authors. 